\title{
«Al privato onesto un'arma legittima». Per una genealogia della legittima difesa tra il moderamen inculpatae tutelae e la difesa legittima del diritto penale fascista
}

\author{
Domenico Siciliano*
}

\section{Oggetto e problematizzazione}

L'oggetto del presente articolo è l' istituto della legittima difesa a tutela della proprietà o dei beni patrimoniali nell'ordinamento giuridico italiano. Per problematizzare questo istituto giuridico estremamente attuale si procederà, nella scia di Michel Foucault, a una «diagonalizzazione del presente», a fare quella che, sempre con Foucault, che a sua volta si rifà a Friedrich Nietzsche, può essere chiamata una «genealogia». Si tratterà non della storia, ma di una storia della legittima difesa a tutela della proprietà nel diritto penale italiano.

Inizierò pertanto dal 'passato'. La discontinuità che vorrei marcare è nel passaggio dalla disciplina del moderamen inculpatae tutelae, sottesa ancora ai codici preunitari, in particolare il Codice penale toscano del 1853 e il Codice sardo del 1859, e al primo Codice penale unitario, il Codice italiano Zanardelli del 1889, secondo la quale fondamentalmente si può uccidere a tutela solo della vita e dell'incolumità

\footnotetext{
Università degli Studi di Firenze. La citazione nel titolo è di Arturo Rocco. Il presente testo è una rielaborazione, aggiornamento e integrazione di un articolo pubblicato nel 2019 in «Questione giustizia» on line con il titolo: «Al privato onesto un'arma legittima». Una genealogia della legittima difesa a tutela del patrimonio nel sistema giuridico italiano. Ringrazio Francesco Vertova per aver letto parti di una versione precedente del manoscritto e aver dato preziose indicazioni e consigli.
} moderamen inculpatae tutelae e la difesa legittima del diritto penale fascista, pp. 39-93, ( 2020 Author(s), CC BY 4.0 International, DOI 10.36253/978-88-5518-202-7.05, in Piero Barucci, Piero Bini, Lucilla Conigliello (edited by), I mille volti del regime. Opposizione e consenso nella cultura giuridica, economica e politica italiana tra le due guerre, (C) 2020 Author(s), content CC BY 4.0 International, metadata CC0 1.0 Universal, published by Firenze University Press (www.fupress.com), ISSN 2704-5919 (online), ISBN 97888-5518-202-7 (PDF), DOI 10.36253/978-88-5518-202-7 
fisica, a quella del diritto alla difesa legittima del Codice Rocco del 1930, come diritto a difendere con la violenza fisica tendenzialmente tutti i beni, proprietà inclusa. Per ragioni di spazio mi limiterò in questo contributo al Codice penale sardo e al suo 'diretto discendente', il Codice penale unitario del 1889, il Codice penale Zanardelli ${ }^{1}$.

\section{La legittima difesa come moderamen inculpatae tutelae}

Il punto di partenza è dato dal paradigma del moderamen inculpatae tutelae, che a seguire verrà ricostruito considerando da un lato le discipline della legittima difesa nel Codice penale sardo e nel suo 'diretto discendente', il Codice penale Zanardelli, e dall'altro la concezione liberale della legittima difesa a esse 'corrispondente' nella giuspenalistica del tempo.

\subsection{Il codice sardo del 1859}

Il codice sardo piemontese del 1859 provvede a disciplinare esplicitamente e in positivo la legittima difesa come causa che esclude la punibilità dell'omicidio o della lesione personale.

L'art. 559 stabilisce: «Non vi è reato quando l'omicidio, le ferite, o le percosse sono comandate dalla necessità attuale di legittima difesa di sé stesso o di altrui, od anche del pudore in atto di violento attentato».

L'art. 560 aggiunge:

Sono compresi nei casi di necessità attuale di legittima difesa i due seguenti:

1) Se l'omicidio, le ferite, le percosse abbiano avuto luogo nell'atto di respingere di notte tempo la scalata, la rottura di recinti, di muri, o di porte d'entrata in casa o nell'appartamento abitato o nelle loro dipendenze;

2) Se hanno avuto luogo nell'atto della difesa contro gli autori di furti o di saccheggio eseguiti con violenza verso le persone $e^{2}$.

L’art. 563 regola poi l'eccesso di difesa:

L'omicidio commesso per eccesso nella difesa della vita o del pudore, o per eccesso nell'esercizio della forza pubblica, è punito col carcere. Colla stessa pena è punito l'omicidio che, per eccesso nella difesa, sia commesso di giorno nell'atto di respingere lo scalamento o la rottura di recinti, muri, porte, finestre di una casa, o di un appartamento abitato, o di luoghi dipendenti da abitazione.

Mentre l'art. 559 ammette in via generale la non imputabilità dell'agente con riferimento alla difesa della vita e dell'incolumità fisica (legittima difesa di

1 Mi permetto di rimandare per l'analisi della disciplina del Codice penale toscano del 1853 al mio Della violenza nel diritto penale fascista. Il caso della legittima difesa a tutela del patrimonio, Libreria Alfani, Firenze 2013, p. 13 sgg.

2 Si veda I. Mel (a cura di), Diritto penale positivo italiano illustrato per articoli con la giurisprudenza pratica formatasi dal 1860 al 1885, Ferrante, Napoli 1885, p. 221 sg. 
se stesso o di altri), aggiungendo inoltre la difesa della «pudicizia» (dell'onore 'sessuale' della donna minacciata di una violenza sessuale), l'art. 560 prevede alla prima ipotesi l'uccisione del fur nocturnus e alla seconda ipotesi l'uccisione del ladro che, esercitando «violenza verso le persone» divenga di per sé un pericolo anche per l'incolumità fisica dell'aggredito nella proprietà. A far da discrimine tra la legittima difesa (art. 559 e 560 n.1) e l'eccesso della stessa (art. 563) è in un caso importante la mera distinzione tra fur diurnus e fur nocturnus.

\subsection{Codice Zanardelli del 1889}

Nel 1889 viene approvato il Codice Zanardelli. La difesa legittima è disciplinata ora nella parte generale sotto il titolo IV Della imputabilità e delle cause che la escludono o la diminuiscono.

L'art. 49 co. $1 \mathrm{n} .2$ sancisce in via generale: «Non è punibile colui che ha commesso il fatto [...] per esservi stato costretto dalla necessità di respingere da sé o da altri una violenza attuale e ingiusta».

L'art. 50 disciplina l'«eccesso scusabile»:

Colui che, commettendo un fatto nelle circostanze prevedute nell'articolo precedente, ha ecceduto i limiti imposti [...] dalla necessità, è punito con la detenzione per un tempo non inferiore ai sei anni, ove la pena stabilita per il reato commesso sia l'ergastolo, e negli altri casi con la pena stabilita per il reato medesimo ridotto a misura non inferiore a un sesto e non superiore alla metà, sostituita la detenzione alla reclusione el'interdizione temporanea dai pubblici uffici all'interdizione perpetua.

Dal momento che la norma dell'art. 49 co. $1 \mathrm{n}$. 2 prevede espressamente la sussistenza di una «violenza», l'aggressione contro i beni non è di per sé rilevante ai fini della sussistenza della legittima difesa. Essa diviene invece rilevante se integra anche una minaccia per la integrità personale. Nel titolo IX Dei delitti contro la persona l'art. 376 prevede infatti per il caso dell'omicidio e delle lesioni personali quanto segue:

Non è punibile colui che ha commesso alcuni dei fatti preveduti nei capi precedenti [si tratta dei capi intitolati Dell'omicidio e Della lesione personale] per esservi stato costretto dalla necessità:

1) di difendere i propri beni contro gli autori di alcuno dei fatti preveduti negli articoli 406, 407, 408 e 410, o dal saccheggio;

2) di respingere gli autori di scalata, rottura o incendio alla casa o ad altro edifizio di abitazione o alle loro appartenenze, qualora ciò avvenga di notte; ovvero qualora la casa o l'edifizio di abitazione o le loro appartenenze siano in luogo isolato, e vi sia fondato timore per la sicurezza personale di chi vi si trovi. La pena è soltanto diminuita da un terzo alla metà, e alla reclusione è sostituita la detenzione, se vi sia eccesso nella difesa, nel caso indicato nel numero 1 del presente articolo; ovvero se il fatto sia commesso nell'atto di respingere gli 
autori di scalata, rottura o incendio alla casa o ad altro edificio di abitazione, o alle loro appartenenze, e non concorrano le condizioni prevedute nel numero $2^{3}$.

Dietro la molteplicità delle ipotesi, delle fattispecie di cui all'art. 376, si intravede la sagoma del fur nocturnus del diritto romano e del diritto comune, del 'ladro' che si insinua nella casa di abitazione nottetempo. La sua attività è di per sé pericolosa. Potrebbe non trattarsi di un semplice ladro, ma di un assassino. Il rischio viene esternalizzato sull' intruso. Nel dubbio, il proprietario può ucciderlo.

\subsection{La scienza penalistica dominante (Carrara)}

La concezione della difesa legittima sostenuta nella dottrina che può essere addotta qui come paradigmatica quanto a sintonia con la disciplina del Codice penale sardo e poi con quella del suo 'successore', il Codice penale Zanardelli del 1889, è la concezione di Francesco Carrara. Nello stesso anno della promulgazione del Codice penale sardo Francesco Carrara apre il suo corso accademico presso l'Università di Pisa con la prolusione Diritto della difesa pubblica e privata ${ }^{4}$. Là dove la difesa pubblica non arriva, e solo nella misura in cui la difesa pubblica non arriva, in implicita stretta sussidiarietà, vige secondo Carrara la «difesa privata». Secondo Carrara «la legge di natura» avrebbe affidato «all'autorità sociale la difesa dell'ordine esterno $\gg^{5}$. Sorgerebbe quindi il problema del conflitto tra tale «difesa dell'ordine esterno» affidata alla «autorità sociale», in bre-

3 L'art. 376 co. $1 \mathrm{n} .1$ rinvia alle disposizioni disciplinanti la rapina, l'estorsione, il ricatto e il saccheggio. In particolare l'art. 406 recita: «Chiunque, con violenza o con minaccia di gravi danni imminenti alla persona o agli averi, costringe il detentore o altra persona presenti sul luogo del delitto a consegnare una cosa mobile o a soffrire che egli se ne impossessi, è punito con la reclusione da tre a dieci anni. Alla stessa pena soggiace chiunque, nell'atto di impossessarsi della cosa mobile altrui o immediatamente dopo, usa contro la persona derubata o accorsa sul luogo del delitto la violenza o la minaccia suaccennata per commettere il fatto o per trasportare la cosa sottratta o per procurare la impunità di sé stesso o di un'altra persona che sia concorsa nel delitto. Se la violenza sia diretta unicamente a strappare la cosa di mano o di dosso alla persona, il colpevole è punito con la reclusione da uno a cinque anni». L'art. 407 recita: «Chiunque, con violenza o con minaccia di gravi danni alla persona o agli averi, costringe taluno a consegnare, sottoscrivere o distruggere, in pregiudizio di sé o di altri, un atto che importi qualsiasi effetto giuridico, è punito con la reclusione da tre anni a dieci anni». L'art. 408 recita: «Quando alcuno dei fatti preveduti negli articoli precedenti sia commesso con minaccia nella vita a mano armata, $\mathrm{o}$ da più persone delle quali anche una sola sia palesemente armata, $\mathrm{o}$ da più persone travisate, ovvero se sia commesso mediante restrizione della libertà personale, la reclusione è da cinque a quindici anni». L'art. 410 recita: «Chiunque sequestra una persona per ottenere da essa o da altri, come prezzo della liberazione, danaro, cose o atti che importino qualsiasi effetto giuridico, a favore proprio o di altri da lui indicati, ancorché non consegua l'intento, è punito con la reclusione da cinque a quindici anni».

4 F. Carrara, Diritto della difesa pubblica e privata (Prolusione al corso accademico dell'anno 1859-1860), in Id., Opuscoli di diritto criminale, $4^{\circ}$ ed., vol. I, Giachetti, Prato 1885, p. 105 sg.

5 Ivi, p. 133. Corsivo nel testo originale. 
ve: tra la «difesa pubblica» e la «difesa privata». E il criterio per la soluzione del conflitto tra «difesa pubblica» e «difesa privata» è dato per Carrara dalla «giusta necessità ${ }^{6}$, articolato da un lato in termini di sussidiarietà della difesa privata rispetto a quella pubblica e dall'altro secondo il principio di proporzione immanente al requisito della necessità: «Ogni qual volta il presidio della giustizia sociale sia tardo e impotente ad impedire il male che si minaccia, e la difesa privata può con minor male impedirla, altrettante volte risorge il diritto della $\mathrm{di}$ fesa privata; e la necessità del momento porge al tempo medesimo la causa e la misura della legittimità dell'esercizio di lei $>^{7}$.

Carrara si confronta, per confutarle, con le due fondazioni della legittima difesa ovvero del «diritto di propria difesa» dominanti al tempo. Si tratta del principio «della collisione degli uffici» e del principio «di perturbazione», per la considerazione dei quali mi permetto qui per ragioni di spazio di rimandare ad altro scritto ${ }^{8}$. Mi concentrerò a seguire solo sulla pars costruens di Carrara, ricostruendo brevemente la fondazione proposta da Carrara, fornita ricorrendo alla figura della «cessazione del diritto di punire nell'autorità sociale». Questo diritto verrebbe a confliggere con il «diritto di difesa privata» degli uomini. Per comprendere in quali casi si verifichi tale conflitto può essere utile un passo in cui Carrara provvede a dare contenuto materiale al «gius di punire», al «diritto di punire» grazie al concetto di «legge di natura»:

Il gius di punire nella società emana dalla legge di natura. Ma la legge di natura ha dato all'uomo, più che il diritto, il dovere di conservare la propria esistenza. Questo è precetto della legge primitiva, come lo èl'associazione degli uomini, la loro subiezione ad un'autorità, e la forza coattiva in mano di questa pel mantenimento dell'ordine. I due precetti primitivi - precetto all'uomo della conservazione di sé stesso - subiezione dell'uomo a una pena qualora turbi l'ordine esterno - non possono non essere coordinati fra loro. Se sono coordinati, il secondo precetto non può essere derogativo del primo; mentre anzi ha questo con quello una esattissima convergenza, perché entrambi tendono alla conservazione dell'uomo. Dunque ove parla il primo precetto deve tacere il secondo?.

In tal modo il criterio materiale per il 'coordinamento', oggi si direbbe per il 'bilanciamento', è dato dal principio di autoconservazione dell'uomo ovvero conservazione della vita, rispetto al quale il principio del «mantenimento dell'ordine» e del «gius di punire» stesso è finalizzato. La «contraddizione» tra il diritto alla vita garantito dalla legge di natura e il diritto a punire, anch'esso garantito dalla legge di natura, viene risolta dando la prevalenza al diritto alla vita dell'individuo:

9 Carrara, Diritto della difesa pubblica e privata, cit., p. 143 sg. 
È impossibile che la legge di natura, la quale ha detto all'uomo non ti lasciare uccidere, abbia detto all'autorità, uccidi o punisci quell'uomo perché non si è lasciato uccidere. Dunque, quando l'uomo ha obbedito al precetto naturale della propria conservazione, senza che a lui possa farsi rimprovero o di colpa nelle cagioni, o di eccesso nell'esercizio, non esiste più autorità che lo possa colpire, perché la legge di natura che ha dato all'autorità il diritto di punire non può contraddire sé stessa. Laonde con tutta esattezza si deve affermare che il gius di punire è cessato nell'autorità umana, rimpetto all'uomo che altro non ha fatto se non provvedere alla necessità della conservazione di una vita innocente ${ }^{10}$.

Di fronte al dovere ovvero alla necessità di conservazione di una vita innocente, e quindi di fronte ai 'diritti dell'uomo', cede il 'diritto dell'autorità' di punire. I 'diritti dell'uomo' risultano in tal modo serbati e non oggetto di disposizione. Il diritto alla vita dell'aggredito viene mantenuto e affermato. Quanto al diritto alla vita dell'aggressore, la sua soppressione viene neutralizzata ovvero occultata dal punto di vista discorsivo nel momento in cui a venir meno è il diritto dello Stato a punire. È la legge di natura e più precisamente il suo contenuto materiale a dare il tono del conflitto. A essere affermato paradigmaticamente è il diritto alla vita ovvero il diritto sorto dalla «necessità della conservazione di una vita innocente $\gg$. Carrara specifica quindi tale concezione per il caso della «incolpata difesa $\gg$, ovvero del moderamen inculpatae tutelae ${ }^{11}$, il cui «principio della legittimità » sarebbe da ravvisarsi sempre «nella cessazione del gius di punire»:

Infatti, tostoché la legge di ordine non viene a turbarsi con la impunità, non vi è più ragione di punire. Ora la legge di ordine con la impunità non si turba, quando il fatto fu impeditivo di maggior disordine [...]. Se avvenne che un diritto rimanesse violato, l'azione che lo violò non causò nel suo risultamento disturbo dell'ordine quando fu necessaria ad impedire il sacrificio di un diritto uguale o più importante di quello violato ${ }^{12}$.

Il criterio per la soluzione del conflitto tra il diritto di punire e il diritto dell'aggredito è dato in definitiva dal rapporto valoriale o di importanza tra i diritti degli uomini in conflitto. Solo se il diritto dell'aggredito è di valore pari o superiore a quello dell'aggressore la difesa risulterà legittima. Carrara non specifica ulteriormente questo criterio con riferimento al caso della difesa mortale dei beni. Se però si ricollega il principio qui enunciato da Carrara a quanto da lui affermato nella specificazione del contenuto materiale della «legge di natura», si può sostenere

10 Ivi, p. 144. Corsivo nel testo originale.

11 L'espressione moderamen inculpatae tutelae si riscontra per la prima volta in un rescritto di Diocleziano e Massimiano del 290 d.C., C. 8.4.1.: «Recte possidenti ad defendendam possessionem, quam sine vitio tenebat, inculpatae tutelae moderatione illatam vim propulsare licet». Tuttavia la figura giuridica del moderamen inculpatae tutelae viene precisata e articolata solo in epoca medioevale, prima dai Canonisti e poi dai Legisti. Vedi ampiamente qui K. Pennington, Moderamen inculpatae tutelae: The Jurisprudence of a Justifiable Defense, «Rivista internazionale di diritto comune», 24, 2013, p. 27 sgg., p. 30 sgg.

12 Carrara, Diritto della difesa pubblica e privata, cit., p. 147. Corsivo nel testo originale. 
che nella concezione di Carrara implicitamente non v'è spazio per la difesa mortale della proprietà. Solo la messa in pericolo dell' incolumità fisica ovvero della vita dell'aggredito possono dare luogo alla violazione del diritto alla vita del ladro ovvero del rapinatore e quindi far venir meno il 'diritto' dello Stato di punire.

Tale conclusione si lascia corroborare alla luce dell'analisi della concezione di Carrara sulla legittima difesa esposta nel Corso del 1867. Carrara considera anche qui la legittima difesa come un caso di coazione, nel quale la coazione conduce non a una «azione» volta a scongiurare una «violenza [che] procede o dal caso o da un terzo», diretta «contro una persona che non era causa del male stesso», per intendersi: quello che sarà successivamente chiamato «stato di necessità» 一, ma a una «reazione», che si rivolge contro l'aggressore, con le parole di Carrara, che si ha «quando per liberarci dal pericolo imminente respingiamo quell'istesso che a noi lo minaccia, e pel bisogno della difesa nostra non ci limitiamo alla semplice repulsa dell'attacco, ma procediamo ancora alla offesa dell'aggressore $»^{13}$. In entrambi i casi per Carrara «cessa l'imputabilità, sì dell'azione come della reazione, quantunque in loro si configuri un fatto materialmente contrario alla legge, purché nel timore che ci ha spinto ad agire o reagire ricorrano gli estremi di quello che i criminalisti appellano moderame dell' incolpata tutela, o con formula più completa, necessita $\grave{{ }^{14}}{ }^{14}$. Carrara riprende espressamente quanto da lui illustrato nel suo $<$ discorso sulla difesa pubblica e privata», ravvisando come «fondamento giuridico della scriminazione», invece che il principio della «collisione degli uffici» o quello della «perturbazione dell'animo», quello della «cessazione del diritto di punire nella società $\gg^{15}$. Decisiva ai fini della determinazione della «forza escusante della coazione $\gg^{16}$ è solo la posizione dell'aggredito, non quella «[d] ell'aggressore $\mathrm{o}$ [d] ella vittima del fatto». In tal modo si potrà decidere secondo Carrara della legittimità del «furto commesso per necessità di fame», cioè del caso centrale di «stato di necessità», così come tematizzato per esempio da Hegel nel $\ 127$ della sua Rechtsphilosophie. E qui, con riguardo allo stato di necessità, Carrara ricorre all'importante differenza irreparabile vs. reparabile per 'giustificare' il 'bilanciamento' fatto a favore della vita: «La legge dell'ordine non può preferire il male irreparabile della morte di un uomo, al male reparabile della offesa proprietà: essa è legge di conservazione $[\ldots] \gg \gg^{17}$. Carrara individua quindi tre requisiti in presenza dei quali «un atto violatore dei diritti altrui e materialmente contrario alla legge» possa considerarsi «legittimo». Si tratta dei requisiti della «ingiustizia», della «gravità» e della «inevitabilità » del «male minacciato». In particolare, con riferimento al requisito della «gravità», Carrara osserva:

13 F. Carrara, Programma del Corso di diritto criminale, vol. I, Tip. Giusti, Lucca 1867, p. 168. Corsivo nel testo originale.

${ }^{14}$ Ivi, p. 169. Corsivo nel testo originale.

15 Ivi, p. 170.

16 Ivi, p. 171.

17 Ivi, p. 172. 
La gravità del male non deve cercarsi nell'assoluta verità, che può essere rimasta occulta all'aggredito; ma nella ragionata opinione dell'aggredito medesimo [...]. Si considera come grave il male che minaccia la vita, le membra, e la pudicizia: non quello che attacca la roba: né quello che lede la fama; tranne rispetto ad una reazione correlativa. E sebbene il commento officiale del Codice Bavaro (art. 129 nota 1); il codice di Assia Harmstadt [sic!], e il codice Austriaco, ammettano come causa dirimente la difesa della proprietà, la comune dei dottori e dei legislatori le accordano soltanto una efficacia minorante, che ha la sua ragione nella giustizia dell'affetto motore: ma non mai, quando è isolata, le accordano forza scriminatrice. Carmignani ha ridotto con molta esattezza scientifica il criterio della gravità del male alla sua irreparabilità [...]: e questa è la formula più vera così teoricamente come praticamente $[\ldots]^{18}$.

Qualora venga meno il requisito della « gravità » ovvero della «inevitabilità del pericolo» non si ha più legittima difesa, ma «il così detto eccesso di difesa», laddove Carrara distingue ulteriormente «tra eccesso di difesa che sempre configura il dolo, e eccesso di moderame (o come altri dice, difetto nel moderame) che sempre configura la colpa: e può anche tal volta lasciarsi impunito ${ }^{19}$.

Qui Carrara fa valere la disciplina del Codice penale prussiano del 1851, che appunto prevede nel suo $\$ 41$, accanto alla legittima difesa, la figura dello eccesso, provvedendo a $\ll$ parifica $\left[\right.$ rle] agli effetti della esonerazione $\gg^{20}$ :

Mitissima disposizione, ed accettabile, purché si referisca al difetto (o eccesso) nel moderame, perché in tal senso ha salda base sull'anzidetto principio della cessazione del dolo. Colui che illuso sulla gravità e sull' inevitabilità del proprio pericolo, uccide o ferisce, non ha la volontà, non ha la coscienza di delinquere. Egli non è assolutamente in dolo ${ }^{21}$.

Qui il delinquente a cui Carrara pensa è quello centrale nel diritto penale liberale, colui che vuole il fatto di reato, in modo assai simile a quello con il quale vuole concludere un contratto o costituire un'impresa. Resta, nel vero senso della parola, eventualmente la categoria del reato colposo: «Gli si può rimpro-

18 Ivi, p. 173 sg. Corsivo nel testo originale.

19 Carrara, Programma del Corso di diritto criminale, cit., p. 178.

20 Ibidem. Il $\$ 41$ del Codice penale prussiano del 1851 recita: «Ein Verbrechen oder Vergehen ist nicht vorhanden, wenn die That durch die Notwehr geboten war. Nothwehr ist diejenige Vertheidigung, welche erforderlich ist, um einen gegenwärtigen rechtswidrigen Angriff von sich selbst oder Andern abzuwenden. Der Nothwehr ist gleich zu achten, wenn der Thäter nur aus Bestürzung, Furcht oder Schrecken über die Grenzen der Vertheidigung hinausgegangen ist». «Un delitto o una contravvenzione non sussiste, se il fatto era richiesto dalla legittima difesa. Legittima difesa è quella difesa che è necessaria per respingere da sé o altri un'aggressione attuale e antigiuridica. Va egualmente considerata la legittima difesa quando il reo è andato oltre i confini della difesa solo per sgomento, paura o terrore». Si veda qui T. Goltdammer, Die Materialien zum Straf-Gesetzbuch für die Preussischen Staaten, Theil I, Heymann, Berlin 1851, p. 417.

21 Carrara, Programma del Corso di diritto criminale, cit., p. 178. Corsivo nel testo originale. 
verare un errore di calcolo, una precipitazione: e così i termini di una colpa $\gg^{22}$. E qui il criterio che interviene a tracciare un'ulteriore differenza è la distinzione tra capacità 'ordinarie' e invece 'straordinarie':

Ma se si avverte che l'aspetto di un pericolo imminente non lascia facoltà di ragionare che ad uomini di straordinaria presenza di spirito, si comprende che cotesta precipitazione, e il conseguitone errore di giudizio, è un effetto inevitabile della umana natura: effetto da cui solo pochissimi andrebbero esenti in circostanze analoghe; cioè nella circostanza di una perturbazione cagionata dal terrore ${ }^{23}$.

È quindi l'incidenza del terrore, il suo effetto sugli uomini 'ordinari', quelli che non godono «di straordinaria presenza di spirito», a far andare esente da pena in sintonia con la concezione immanente al $\$ 41$ del Codice penale prussiano del 1851.

Sempre nel 1867 nel vol. IV della Parte speciale, nella parte dedicata ai furti, Carrara affronta la questione del furto che avviene durante la notte, che rileverebbe soprattutto sotto il profilo «del pericolo della persona»:

Quando la forma del furto porta il ladro a contatto della persona del proprietario o del suo domicilio, allora il tempo notturno non solo agevola il reato e rende più difficile la difesa della proprietà, ma di più fa sorgere grave sospetto di pericolo anche per la vita e per la salute del proprietario ${ }^{24}$.

Carrara ricorda che il Codice penale toscano non dà rilievo alla circostanza del tempo di notte per il furto, mentre invece quello Sardo all'art. $368 \mathrm{n} .1$ «la valuta quando congiunta a quella della casa abitata», dando inoltre una (pericolosa!) definizione legislativa della notte, come «tutto quel tempo che corre da un'ora dopo il tramonto a un'ora prima della levata del sole $\gg^{25}$. In presenza appunto di una legge che «ad una pagina dice al ladro, ti punirò meno se ruberai di giorno, e così rende favorevole all'accusato il prolungamento del giorno giuridico; ad un'altra pagina dice al proprietario, ti punirò meno o niente se ucciderai il ladro di notte, e così rende favorevole all'accusato il prolungamento della notte giuridica $\gg^{26}$, si potrà allora discutere non poco in giudizio nel caso in cui il proprietario aggredito in casa da «una mano di ladri in sull'aurora», svegliatosi improvvisamente «corra sull'arme e uccida uno di coloro $\gg^{27}$. Il proprietario accusato di omicidio e i ladri superstiti cercheranno

22 Ibidem.

23 Ivi, p. $178 \mathrm{sg}$. Corsivo nel testo originale.

24 F. Carrara, Programma del corso di diritto criminale dettato nella R. Università di Pisa. Parte speciale ossia esposizione dei delitti in specie con note per uso della pratica forense, vol. IV, Lucca 1867, p. 307.

25 Ivi, p. 309.

26 Ivi, p. 311.

27 Ibidem. 
di 'dipingere' la zona d'ombra del crepuscolo dal punto di vista interpretativo: ancora notte per il primo, già giorno per i secondi. Carrara fa leva qui sul principio del favor rei:

Nello sciogliere siffatto nodo il giudice che non comprenda il senso relativo e tutto applicativo del favore della difesa regolando su tale stregua la teorica del crepuscolo, troverà difficoltà a dire nella stessa sentenza che quello identico momento era giorno ed era notte. Oppure dovrà porre sulla bilancia la prevalenza di favore tra il ladro e l'omicida? ${ }^{28}$.

Carrara, qui in notevole sintonia con Kant, fa valere la «interpretazione filosofica», che oppone con decisione alla lettera la ratio della disposizione di legge:

No. Il giudice filosofo non s'impaccierà per tali apparenti ambagi, e si sbrigherà dalla lettera della legge per correr dietro al suo spirito. Egli dirà che nel crepuscolo non ricorrono le ragioni per aggravare la mano sul ladro, e negherà la qualifica: indi guarderà le ragioni della apprensione di proprio pericolo che scusano l'omicida, e ammetterà la scusa. Ed a chi gli venga rinfacciando di essersi contradetto risponderà non esser chiamato a dare una definizione astronomica, ma a dare una definizione giuridica; dirà non essere una materialità ciò che scusa od aggrava, ma bensì una suprema ragione che ora può accompagnare, ed ora no la identica materialità ${ }^{29}$.

Insomma: il criterio interpretativo nell'uno come nell'altro caso è il favor rei, che arriva per mezzo dell' interpretazione 'filosofica' ovvero 'secondo la ratio/lo spirito' a 'superare' la lettera della disposizione punitiva in questione. Il che per il caso dell'uccisione del fur nocturnus significa che nella prospettiva di Carrara (non solo ma soprattutto) sotto la vigenza del Codice sardo del 1859 - sotto più profili il principale obiettivo polemico del penalista toscano - e quindi alla luce dei corrispondenti artt. 558, 559 e soprattutto $560 \mathrm{n}$. 1, il diritto penale deve essere liberale, tanto nei confronti dei ladri quanto nei confronti dei proprietari.

Pochi anni dopo, nel 1874, nei Lineamenti di pratica legislativa penale, all'Osservazione $I V$, tesa ad evidenziare le 'ragioni' dell'elemento volitivo del soggetto agente a scapito di quella che Carrara chiama «materialità $»$, dopo un $\$ 1$ dedicato alla questione della «scalata», nel $\$ 2$ Carrara torna sulla questione del «tempo di notte». Il Codice penale toscano con la disposizione ampia e flessibile dell'art. 34 (e dell'art. 64) glissa sulle «cause materiali» ovvero sulla «causa mediata $»$, e quindi «non defin[isce] l'errore, non la ubriachezza, non la pazzia, non il moderame, non la provocazione, non il giusto dolore maritale o paterno, non la repulsa dei ladri, non altre condizioni eccezionali che modificano la imputabilità $\gg^{30}$ e invece si dedica correttamente, secondo Carrara, alla «cau-

28 Ivi, p. $311 \mathrm{sg}$.

29 Ivi, p. 312.

30 F. Carrara, Lineamenti di pratica legislativa penale esposti mediante svariate esemplificazioni, Bocca, Roma, Torino, Firenze 1874, Osservazione IV, p. 113 sgg., p. 126. 
sa immediata» ovvero alla «causa giuridica», che è data dalla «modificazione morale dell'atto umano; modificazione consistente nel difetto di coscienza e di libertà ${ }^{31}$, in altri termini: dal difetto del momento cognitivo e volitivo del reo. Al contrario, il Codice penale sardo provvede a disciplinare nel dettaglio, quasi alla lettera nella scia del Codice penale francese, la legittima difesa e in specie tutta una serie di aggressioni alla proprietà che evocano la figura romanistica dell'uccisione del fur nocturnus. Qui lo scopo di Carrara è accentuatamente di 'politica del diritto penale'. Con riguardo proprio alla questione della concretizzazione della distinzione giorno/notte in riferimento all' interpretazione dell'art. $560 \mathrm{n} .1$ del Codice penale sardo, Carrara stigmatizza il «letto di Procuste» sul quale sarebbe 'costretto' a stendersi il giudice che deve applicare il Codice penale sardo, a differenza di quello che deve applicare il Codice penale toscano. Il punctum dolens, spiega il giurista toscano, è dato dall'uccisione per respingere la scalata o l'irruzione che avvenga nella 'linea d'ombra' del crepuscolo, ravvisabile 'alla luce' dell'art. 613 del Codice penale sardo come l'ora successiva al tramonto del sole e quella che precede la levata dello stesso. L'uccisione avvenuta al crepuscolo esclude per l'aggredito il tempo di notte di cui all'art. $560 \mathrm{n} .1$ ? Carrara, che rimanda in generale espressamente a quanto da lui già esposto $\mathrm{e}$ sostenuto nel suo Programma ${ }^{32}$, qui fa un passo ulteriore, al solo fine di evidenziare con chiarezza una 'lacuna valoriale' nel Codice penale sardo.

Non si aspetti da me che io qui pronunzi la mia opinione su questa possibile controversia $[\ldots] .[\mathrm{L}] \mathrm{o}$ scopo di questo mio scritto non è già quello di cercare la soluzione di uno od altro problema di giure penale. Il suo scopo è meramente quello di mostrare mediante alcune delle più notevoli esemplificazioni $i$ pericoli delle definizioni nel giure punitivo $[\ldots]$. Dirò soltanto, come generalità, che nell'applicazione dell'art. $560 \mathrm{n}$. 1 del Codice Sardo vuolsi usare di ogni maggiore larghezza, fissando sempre il pensiero sulla situazione soggettiva dell'uccisore. Volete voi che quando io ascolto i ladri urtare l'uscio della mia camera per introdurvisi corra prima a guardare il mio orologio per sapere qual'ora è; e poscia cerchi il lunario per conoscere a qual'ora in quel mattino incominci il crepuscolo, ed a qual'ora si levi il sole, e soltanto dopo tali verificazioni fattomi certo che io verso nel periodo legittimo, dia di piglio all'archibugio e lo esploda contro gli aggressori! Sono queste tali cose che si possono dire e sostenere sul serio? E se io non possedo orologio, se non so leggere nel lunario, se nel mio contado non v'è campana che suoni le ore, se il giorno è sì fosco che arrieggi a notte quantunque da un buon quarto d'ora sia comparso il sole all'orizzonte, ma velato da foschissime nubi; dovrò io essere responsabile di tali accidentalità, mentre al rompersi improvviso dell'alto mio sonno io credetti di essere nel colmo della notte? ${ }^{33}$.

31 Ivi, p. 126.

32 Vedi ivi, p. 123.

33 Ivi, p. 123 sg. Corsivo nel testo originale. 
Carrara ha buon gioco nel farsi beffe della distinzione fur diurnus vs. fur nocturnus presa 'alla lettera' senza andare a cercarne il 'fondamento'. Può infatti porre il lettore tra la scelta per l'applicazione della lettera dell'art. 563, e quindi la condanna per eccesso di difesa dell'aggredito, oppure per l'interpretazione 'secondo la ratio'/'secondo lo spirito' a favore del proprietario aggredito. E il criterio, la ratio, e qui sta lo spostamento rispetto a quanto asserito sul punto da Carrara nel Programma, è dato non dal favor rei ma dal favor per il reus che è proprietario e si difende contro i malfattori, in un'ottica assai 'moderna' di prevenzione generale positiva:

Vi parrà egli che sia obbedita la giustizia subiettiva col fare ricadere sul capo del proprietario le conseguenze dell'altrui scelleratezza? No, perché ingiusta è la pena quantunque minima che colpisce l'uomo il quale non ebbe coscienza di delinquere: No, perché neppure potete rimproverare imprudenza ad un infelice che usò tutta quella prudenza che era possibile in quella paurosa e repentina costernazione. Vi parrà egli che ciò si esiga dalla giustizia obiettiva? No, perché gli onesti cittadini non si atteggiano a timore per la sorte del ladro, la quale per se stessi non prevedono possibile; ma si commuovono invece all'aspetto della pena che ha colpito un loro simile, ed alla quale prevedono il pauroso possibile di soggiacere innocenti alla volta loro. Il danno mediato non nasce dalla uccisione, ma dalla pena che infliggete all'uccisore. Col punire incoraggiate i malfattori e spaventate gli onesti, la vostra pena, non è né giusta, né politica ${ }^{34}$.

$\ll$ E come potrete trarvi da simile impaccio? ${ }^{35}$, chiede quindi retoricamente Carrara ai suoi lettori. «No way out»! La dettagliata disciplina del Codice penale sardo impedisce di richiedere la acclamatio di Gaiana tradizione: «Vorrete forse andar cercando se il proprietario poteva o no utilmente acclamare?» chiede Carrara. «Voi lo potreste», osserva, «sotto altri codici, i quali con miglior senno, anziché copiare dal Codice francese le due grette condizioni materiali della scalata (o effrazione) e del tempo notturno, hanno tenuto conto del criterio più razionale della solitudine del luogo; oppure, con senso più pratico, hanno trovato il criterio del tempo notturno nelle abitudini locali della destinazione al sonno. Ma sotto il codice vostro», nota Carrara, «voi ciò non lo potete, perché esso (peggiorando forse sul codice di Francia) inesorabilmente impone il criterio del centimetro e dei cinque minuti ${ }^{36}$. Passiamo ora alla seconda 'contraddizione': che fare nel caso in cui non vi sia più il dubbio sulla concretizzazione della differenza notte/giorno, si sia varcata la 'linea d'ombra' del crepuscolo e il proprietario abbia, è il caso di dirlo, 'chiaramente' ucciso il ladro 'alla luce del sole', in pieno giorno, «cinque o dieci minuti dopo l'ora della levata del sole». Ecco la palese contraddizione per Carrara:

34 Ivi, p. 124.

35 Ibidem.

36 Ivi, p. 124 sg. Corsivi nel testo originale. 
Lo scatto di una campana decide della sorte del proprietario! Cinque minuti innanzi esso non fu colpevole, quantunque preferisse uccidere l'aggressore del suo domicilio anziché acclamare ai numerosi domestici che gagliardi gli stavan d'appresso, od acclamare ai vicini che stavano folti in prossimità della sua abitazione nel centro di popolosa città. Ma cinque minuti dopo il proprietario è un colpevole, quantunque egli fosse solo in quella sua casa, e quantunque questa giacendo in località solitaria e remota lo rendesse deserto di ogni speranza ragionevole di soccorso altrui e di intimidazione degli aggressori! ${ }^{37}$.

La lettera del Codice penale sardo inchioda in modo 'irragionevole' il proprietario che abbia avuto la sventura di uccidere il fur nocturnus trasformatosi repentinamente in diurnus: «Avete forse speranza di applicare al proprietario la regola del moderame? Voi lo potreste sotto altri codici; ma non lo potete sotto il codice vostro; non lo potete senza violare la lettera dell'art. 560 [...]. Laonde non havvi interprete il quale nella disposizione che comprende tra $i$ casi di legittima difesa la repulsa dei ladri in tempo di notte, non si trovi costretto a leggere la disposizione avversativa, che cioè la repulsa dei ladri in tempo diurno non è compresa nei casi di legittima difesa. Dicendo altrimenti», conclude Carrara, «non s'interpreta ma si conculca la lettera della legge ${ }^{38}$. Insomma: da un lato la 'giusta' interpretazione nell'ambito dei possibili significati letterali, il 'diritto' come Rechtsgrund, come 'ragione giuridica', con la Entscheidungsfolge ${ }^{39}$, la conseguenza giuridica 'ingiusta' della decisione di condanna dell'aggredito, dall'altra la Entscheidungsfolge, la conseguenza giuridica 'giusta' dell'assoluzione, purtroppo però contra legem, cioè contro i Rechtsgründe, le 'ragioni giuridiche':

Bisogna dunque che il giudice o mentisca alla verità delle cose, dando al giorno il nome di notte; o si faccia egli stesso legislatore: oppure mentisca alla propria coscienza condannando il proprietario ad una pena, e (se fortuna volle che il ladro non fosse ucciso, ma fosse soltanto ferito, e inabilitato al lavoro) condannandolo al perpetuo mantenimento di quel masnadiero ${ }^{40}$.

Carrara infierisce ulteriormente sul Codice penale sardo (e sul relativo legislatore) a favore del più flessibile Codice penale toscano: che succede nel caso in cui il proprietario che è autorizzato dall'art. 560 del Codice penale sardo a «respingere la scalata o la effrazione» intervenga a difesa della sua casa di abitazione in un momento successivo? Ma dunque», chiede retoricamente il professore-avvocato di Lucca, «se la scalata o la effrazione erano già compiute, e già i ladri si aggiravano entro la mia casa, non sarà più legittima la strage che io ne

37 Ivi, p. 125.

38 Ibidem.

39 Vedi qui R. Wiethölter, Zur Argumentation im Recht. Entscheidungsfolgen als Rechtsgründe?, in G. Teubner (ed.), Entscheidungsfolgen als Rechtsgründe. Folgenorientiertes Argumentieren in rechtsvergleichender Sicht, Nomos, Baden-Baden 1995, p. 89 sgg.

40 Carrara, Lineamenti di pratica legislativa penale, cit., p. 126. 
faccia? $>^{41}$. Carrara concede che non pochi problemi nascono dalla ricezione della disciplina del Codice penale francese del 1810 e dalla paradossalmente 'infedele' «traduzione letterale» dei corrispondenti articoli. Così l'espressione dell'art. 329 del Codice penale francese «en repoussant l'escalade», una volta tradotta con «nell'atto di respingere», invece che con «la equivalente formula respingendo $\gg^{42}$ avrebbe ristretto la finestra temporale (e spaziale) della giustificazione. Analogamente Carrara ricorda «che l'originale francese adopera nell'art. 329 n. 1 la frase "effraction de entrée d'une maison"; e che il traduttore italiano ha convertito quella frase nella seguente - "rottura di porte di entrata in casa» ${ }^{43}$. Come in un manuale di teoria dell'interpretazione, arriva la Gretchenfrage, la 'domanda delle cento pistole': «Che dire di un cancello?». Carrara infatti osserva: «Ora la parola porta non rende davvero con esattezza la parola entrée dell'originale. È evidente che una casa può essere chiusa con un cancello, e che un cancello non è una porta $\gg^{44}$. Anche qui il dilemma con il quale si dovranno tormentare i membri della giuria è quello tra interpretazione letterale e interpretazione 'fondamentale':

Il giurato aderente alla lettera della disposizione italiana trovando che non si tentava di rompere una porta, ma soltanto di atterrare un cancello, dubiterà che manchino i termini della eccezionale discolpa. La regola (dirà egli) sta nella colpevolezza di ogni omicidio. La impunità è una eccezione che può accordarsi soltanto dove ricorrono i precisi termini tassativamente descritti dalla legge. Siffatti termini io qui non trovo, e non posso accordare impunità ad un omicida. Sarà costui troppo rabbinicamente attaccato alla lettera della legge; ma pure è possibile che lo sia» ${ }^{45}$.

E che dire infine del caso nel quale l'aggressione nel domicilio non avviene tramite scale o tramite effrazioni, ma tramite $\ll$ l'uso di falsa chiave ${ }^{46}{ }^{\text {? }}$ ?

Carrara mostra così, non senza stigmatizzare con una punta di antigiudaismo lo «attacca[mento] alla lettera della legge» dei rabbini, le secche nelle quali lo 'zelo definitorio', il «voler troppo definire» in tema di legittima difesa ha portato il legislatore. Qual è allora il problema secondo Carrara? Due sono le ipotesi esplicative. La prima: «Si è forse temuto che la formula difesa propria od altrui fosse insufficiente, e si è creduto di allargarla con la specificazione dei due casi riprodotti nell'articolo $560 \mathrm{n}$. 1 e 2 ? $\gg^{47}$. Il legislatore, in altri termini, voleva ampliare i casi di legittima difesa del tradizionale moderamen inculpatae tutelae, incentrato sulla difesa mortale di vita e incolumità fisica ed eventualmente

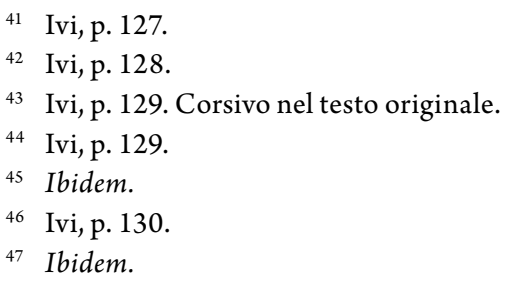


libertà. Ma qui, ricorda Carrara, sarebbe bastata la coppia 'Codice toscano' e 'giuristi toscani', a far sì «che quei due casi rientrino nel diritto della difesa legittima [...] senza bisogno di tante definizioni $\gg^{48}$, laddove Carrara, facendo un generico riferimento alla giurisprudenza toscana, aggiunge di averne egli stesso «avuto gli esempi». L'altra ipotesi esplicativa va nella direzione contraria, ed è la seguente: il legislatore avrebbe voluto evitare «che troppo si allargasse la nozione della difesa legittima $[\ldots] \gg^{49}$. E nel caso in cui tale ipotesi cogliesse nel segno, se cioè «il pensiero del legislatore è stato questo», allora «esso lo ha pur troppo raggiunto col suo linguaggio: ma a parer mio», conclude Carrara, «a scapito della giustizia $\gg^{50}$. In breve: Carrara critica fondamentalmente la formulazione dell'art. $560 \mathrm{n} .1$ e 2 del Codice penale sardo perché questo porta i giurati in taluni casi a decidere certo secondo la legge, ma contro giustizia. E i due casi centrali di lacune 'valoriali', di decisioni 'legali' ma 'ingiuste', sono quelli nei quali il proprietario aggredito nella propria abitazione uccide 1) il fur nocturnus in casi diversi da quello della scalata o della rottura, come l'ingresso con uno stratagemma come le chiavi contraffatte, e 2) il fur divenuto da poco diurnus al di là del caso della difesa della vita e della incolumità fisica.

Alberto Cadoppi richiama l'attenzione su questo testo ${ }^{51}$, nel quale Carrara 'inchioda' la foga definitoria del legislatore sardo, oggi diremmo l'ottusità post-burocratica fatta di («umana, troppo umana») 'intelligenza artificiale', a causa della quale l'ansia di 'coprire tutte le lacune' produce paradossalmente molte più lacune di quelle che si assumono 'riempite'. Cadoppi ricorda in primo luogo la disciplina dei codici penali preunitari, e tra di essi 'naturalmente' il Codice penale sardo, che «confermavano quasi pedestremente $»^{52}$ la disciplina dell'art. 329 del Codice penale francese del 1810, che «in sostanza» portavano a una disciplina che comportava per l'uccisione del ladro che tentasse di entrare «con rottura» nella casa di abitazione «di giorno» non il riconoscimento della legittima difesa, ma la «ipotesi attenuata» dello eccesso di difesa (per il Codice sardo: l'art. 363); in secondo luogo Cadoppi ricorda la circostanza che «nel codice toscano del 1853 non si prevedeva espressamente l'ipotesi dell'uccisione del ladro notturno» e che, pur in assenza di tale previsione legislativa espressa, questa $\ll$ in giurisprudenza $[\ldots]$ era ampiamente riconosciuta $\gg^{53}$, per far quindi valere il passo sopra analizzato ${ }^{54}$ nel quale Carrara dà la priorità agli

48 Ivi, p. 131.

49 Ibidem.

50 Ibidem.

51 A. Cadoppi, "Si nox furtum faxit, si im occisit, iure caesus esto". Riflessioni de lege ferenda sulla legittima difesa, in E. Dolcini, C.E. Paliero (a cura di), Studi in onore di Giorgio Marinucci, Giuffrè, Milano 2006, vol. 2, p. 1386. In realtà Cadoppi si avvale della seconda edizione del 1882 , che con riguardo al passo da lui citato non differisce (nella ricostruzione di Cadoppi) dalla prima del 1874 , da me consultata.

52 Ivi, p. 1384.

53 Ivi, p. 1385.

54 Vedi sopra nota 34. 
interessi degli «onesti $\gg$ rispetto a quelli dei «malfattori $\gg$, e «più in generale» la circostanza che Carrara fosse $\ll \mathrm{d}[$ ell]'opinione che si dovesse mandare esente da pena il difensore anche in tutte quelle ipotesi in cui per paura avesse ecceduto i limiti della legittima difesa $\gg^{55}$, ricordando come lo stesso Carrara sottolineasse «con orgoglio [...] il fatto che il codice di Zurigo del 1871 aveva accolto questa sua tesi - sostenuta fin dal 1864 - con il $₫ 48 \gg^{56}$, che appunto prevede la non punibilità dello eccesso di difesa nel caso in cui l'aggredito avesse «agito soltanto per effetto di sbigottimento, timore o spavento $\gg^{57}$.

Qui va osservato che nel pensiero di Carrara sussiste una qualche tensione da una parte tra la concezione sviluppata nella parte generale del suo Program$m a$, che vede un diritto alla legittima difesa ancora nell'ottica del moderamen inculpatae tutelae classico, con la richiesta, nella scia del maestro Carmignani, che il male scongiurato dalla condotta difensiva lesiva sia grave nel senso di irreparabile e il contestuale riconoscimento che la mera difesa dei beni non scrimina, nonché la proposta (nella prolusione del 1859/1860) di una corrispondente fondazione della legittima difesa privata in conflitto con una giustificazione della legittima difesa mortale dei beni e dall'altra parte una concezione che tende da un lato a evidenziare la 'lacuna valoriale' dell'art. 560 del Codice penale sardo a favore del molto più duttile - e non da ultimo molto più toscano - Codice penale toscano e dall'altro a valorizzare, su di un piano diverso, e quindi non più davvero conflittuale, la disciplina dell'eccesso della legittima difesa ${ }^{58}$. In questo

55 Cadoppi, "Si nox furtum faxit, si im occisit, iure caesus esto", cit., p. 1386.

56 Ibidem.

57 Ibidem, in particolare nota 14, che sul punto cita F. Carrara, Programma del corso di diritto criminale. Parte speciale, Firenze 1909, vol. I, \$ 1331, nota 2. Lo Strafgesetzbuch für den Kanton Zürich del 1871 recita al $\$ 48$ co. 2: «Die Überschreitung der Vertheidigung wird nicht bestraft, wenn der Thäter nur aus Bestürzung, Furcht oder Schrecken gehandelt hat». In tal modo si fa implicito riferimento al $\$ 41$ del Codice penale prussiano del 1851 . Vedi sopra nota 20.

58 Questo emerge implicitamente dall'osservazione con la quale Ennio Amodio contrappone da una parte la mia interpretazione, che fa valere la concezione della gravità nel senso della irreparabilità del danno svolta da Carrara nella sua Parte generale e la corrispondente fondazione della legittima difesa fornita nella sua Prolusione del 1859/1860, e dall'altra parte i passi di Carrara sulfur nocturnus/diurnus fatti valere da Cadoppi, propendendo nella sostanza per la ricostruzione da me fatta: «improponibile l'interpretazione del suo [=di Carrara] pensiero in chiave di convinto sostegno all'estensione del "moderame" ai casi in cuil'aggressione si dirige unicamente contro la "roba" $\gg$. Vedi E. Amodio, A furor di popolo. La giustizia vendicativa gialloverde, Donzelli, Roma 2019, p. 55, in particolare nota 79, con riferimento al mio Per una genealogia del diritto alla legittima difesa: da Carrara ai Rocco, «Quaderni fiorentini per la storia del pensiero giuridico moderno», 35, 2006, p. 723 sg., p. 736. Cfr. anche F. Colao, Paura e legittima difesa. Questioni di "moderame" tra Otto e Novecento, «Quaderno di storia del penale e della giustizia», 1, 2019, p. 129 sgg. Colao ricostruisce la concezione sviluppata da Carrara nella sua Prolusione e nella Parte generale del Programma del suo Corso facendo tra l'altro valere la distinzione tracciata da Carrara tra «male irreparabile della morte di un uomo»e «male reparabile della offesa proprietà » per il furto «compiuto per necessità di fame» anche per il caso della (legittima) «difesa dei beni». Colao sottolinea inoltre la «portata ampia» dell' istituto in Carrara ricordando da un lato il caso dell'uccisio- 
senso la concezione di Carrara si posiziona come concezione 'di cerniera' che, ancora entro il 'vecchio' paradigma del moderamen inculpatae tutelae, cerca di migliorarlo e di rispondere ai nuovi problemi e alle sempre più forti richieste di 'difendere la società' con il 'classico' instrumentario della filosofia del diritto, costruendo un moderamen (inculpatae tutelae) che ha la struttura in sé contraddittoria di un «diritto alla legittima difesa», senza averne (ancora) il contenuto, cioè un 'diritto alla legittima difesa' limitato qualitativamente dal punto di vista dei diritti ovvero dei beni giuridici difesi e che quindi, a ben vedere, 'resta' un moderamen inculpatae tutelae.

Tale ricostruzione si lascia confermare nei suoi tratti generali anche considerando la quinta edizione della Parte generale del Programma del 1886, laddove in una nota apposita Carrara si confronta con $\ll[i]$ modernissimi criminalisti alemanni», che appunto hanno introdotto la distinzione tra legittima difesa e stato di necessità, tradendo una concezione della legittima difesa ancora calibrata sulla difesa di vita e incolumità fisica. Carrara ricorda infatti che «le due forme», cioè legittima difesa vs. stato di necessità ovvero reazione vs. azione «ricadono sempre sotto le medesime regole cardinali», laddove il «rispettivo fondamento giuridico» andrebbe ravvisato «sempre [nel]la coazione della volontà », mentre i «rispettivi limiti e condizioni della escusante» sarebbero da ravvisare «sempre nel moderame, vale a dire nel non avere ecceduto sia nell'agire sia nel reagire, oltre quello che era comandato dal bisogno di salvare noi stessi $>^{59}$. Abbiamo qui una «forza escusante» che, ecco la 'contraddizione', nel caso della legittima difesa non è data da una «scusa», ma da un «diritto». Dopo aver espressamente ricordato, come nella edizione del 1867 , che «[1]a forza escusante della coazione si deve cercare nell'aggredito, non nell'aggressore, o nella vittima del fatto $[\ldots] \gg^{60}$, Carrara stigmatizza come $\ll[\mathrm{e}]$ rrore anche più intollerabile, veramente grossolano [...] quello di coloro che dimentichi dei più elementari principii di diritto penale vorrebbero si desse alla legittima difesa il nome di $s c u s a{ }^{61}$. Come argomenta qui Carrara? Semplice, asserendo in linea con la 'tradizione' che riconosce in capo a chi difenda la propria o altrui vita (o incolumità fisica) un diritto (naturale!) a difendere che giunge anche all'uccisione dello «aggressore ingiusto»:

Quando io ho difeso la mia vita o l'altrui dal pericolo di un male ingiusto grave e non altrimenti evitabile, che minacciava l'umana persona, non ho bisogno di scusa: ho esercitato un diritto: vero e sacro diritto; e meglio può dirsi un vero e sacro dovere, perché tale è la vera conservazione della propria persona. Delitto

ne dei rapitori colti nel sonno da parte delle loro vittime e dall'altro la difesa fatta da Carrara (come avvocato!) in un processo a Lucca, tra l'altro in un caso di omicidio non per la difesa dei beni. Cfr. Colao, Paura e legittima difesa, cit., p. 132.

59 F. Carrara, Programma del Corso di diritto criminale. Del delitto, della pena, il Mulino, Bologna 1993 [5. edizione, 1886], p. 197. Corsivo nel testo originale.

60 Ivi, p. 200.

${ }^{61}$ Ibidem. Corsivo nel testo originale. 
orribile sarebbe il punirmi: è un insulto, prodotto dalla ignoranza o dalla crudeltà, dirmi che si concede una $s c u s a^{62}$.

Insomma, è il moderamen inculpatae tutelae che autorizza a uccidere fondamentalmente solo per sventare un pericolo attuale per la vita e l'incolumità fisica. In modo non dissimile dalla terza edizione del 1867 Carrara tematizza a seguire la questione della determinazione del criterio della gravità del male minacciato, facendo valere la differenza irreparabilità/reparabilità e opponendo alla legislazione positiva del Codice dell'Assia e di quello austriaco la «comune dei dottori e dei legislatori $\gg$, che ricollegano alla difesa della mera proprietà mortale o lesiva della incolumità fisica non una piena «forza scriminatrice» ma «soltanto una efficacia minorante».

\subsection{Le teoriche della legittima difesa}

All'indomani della promulgazione del Codice penale nel terzo volume della sua opera a commento del Codice, al par. 2 dedicato alla legittima difesa, Giulio Crivellari, dopo aver lungamente trattato il «Diritto antico», le «opinioni dei pratici e dei più eminenti giureconsulti dei tempi andati $\gg$ passando per Grozio e Pufendorf, sostiene che «gli elementi necessari alla esistenza del moderame di incolpata tutela $\gg$, cioè della legittima difesa, potrebbero essere ridotti $\ll$ sostanzialmente a due: causa ingiusta, pericolo presente ed inevitabile ${ }^{63}$. Crivellari vede sotto questo profilo una continuità con gli «scrittori moderni». Questi non si sarebbero allontanati «da questi principii, sebbene li a[vessero] divisi e suddivisi $\gg$. Crivellari rende plausibile il suo assunto facendo riferimento alle concezioni di Pessina, Carrara e Puccioni. Secondo Pessina, sempre nella ricostruzione di Crivellari, vi dovrebbe essere 1) una legittimità della difesa «nella sua cagione»; 2) la «necessità dovrebbe essere «attuale» e 3) la «difesa» dovrebbe essere «indirizzata soltanto a respingere la ingiusta aggressione ${ }^{64}$. Quanto a Carrara, perché «al timore si accordi il potente effetto di rendere legittimo un atto violatore dei diritti altrui e materialmente contrario alla legge» egli richiederebbe «per regola assoluta $a$ che il «male minacciato» presenti i requisiti della «ingiustizia $»$, della « gravità», della «inevitabilità». Il male minacciato in particolare verrebbe a essere considerato «inevitabile» ulteriormente qualora fosse «improvviso», «presente» nonché «assoluto». Infine Puccioni richiederebbe la presenza del «timore di un male più grave, o eguale a quello inferito»; che questo male fosse «imprevedibile e improvviso»; che fosse inol-

62 Ibidem. Con ulteriore rimando a Florentino, leg. 3, ff. de justitia et jure: «Quod quisque ob tutelam corporis sui fecerit, iure fecisse existimetur». Corsivo nel testo originale.

63 G. Crivellari, Il Codice penale per il Regno d'Italia interpretato sulla scorta della dottrina, delle fonti, della legislazione comparata e della giurisprudenza, vol. III. Art. 31-60. Degli effetti e della esecuzione delle condanne penali. Della imputabilità e delle cause che la escludono o la diminuiscono, Utet, Torino 1892, art. 49, p. 506. Corsivo nell'originale.

64 Ibidem. Corsivo nel testo originale. 
tre «presente ed inevitabile» ${ }^{65}$. Dopo la sua molto sintetica ricostruzione, Crivellari tira le conseguenze, riconducendo le tre concezioni esposte al minimo comune denominatore della concezione di Nicolini:

In sostanza, la dottrina moderna è concorde con l'antica; vi sarà una diversità di linguaggio, uno sminuzzamento maggiore o minore, ma gli elementi della incolpata tutela non sono che questi, perspicuamente illustrati, come sempre, dal Nicolini: «Che la reazione sia comandata dalla necessità della difesa; cioè che la difesa sia necessaria; che la necessità della difesa sia attuale; che la difesa sia legittima $\gg^{66}$.

Il primo requisito, il requisito della necessità, indicherebbe, secondo il Nicolini, cui Crivellari rimanda con approvazione, «la necessità della difesa propria». Per «difesa propria» si intenderebbe «quel diritto [...] che viene direttamente ed immediatamente dalla propria conservazione, raccomandata dalla natura a ciascheduno ${ }^{67}$. Sempre Crivellari prosegue:

L'esercizio di questo diritto è tutto fisico, quando non si ha coscienza della causa che ci turba; urtati, riurtiamo; spinti, respingiamo la forza fisica che ci percuote. Quando però abbiamo coscienza dell'urto che ci si vuol fare, allora si eccita in noi naturalmente la reazione, ugualmente immediata ed indispensabile, ma effetto di calcolo e di ragione. Vi si mesce sempre la passione; ma il suo principio è che l'uomo, quando fa uso di questo diritto, e per esso viene alle ultime estremità, lo fa sempre non in tutto e per tutto macchinalmente, ma a disegno; e questo disegno non è di far male altrui, né di vendicarsi, né di punire alcuno, ma solamente di conservare sé stesso e salvarsi la vita ${ }^{68}$.

Qui Crivellari vede una sostanziale corrispondenza tra la concezione di Nicolini e quella di Carrara, che richiede la «inevitabilità» del male minacciato:

Se al male che ci minaccia potevamo sottrarci altrimenti che col violare la legge, la violazione deve rimanere imputabile, perchél'arbitrio dell'agente non era più ristretto fra la scelta di due mali ugualmente gravi; e la legge dell'ordine poteva essere osservata, purché egli eleggesse il mezzo innocente col quale avrebbe evitato e il danno proprio e l'altrui ${ }^{9}$.

Possibilità di osservare la legge e allo stesso tempo di mantenere il diritto minacciato sono, osserva Crivellari con nuovo esplicito rinvio a Carrara, gli «altri mezzi innocenti » come la «preghiera», la «acclamazione» o la «fuga». In mancanza di una tale possibilità, il «male» viene a essere «assoluto». A questo

65 Ivi, p. 507.

${ }^{66}$ Ibidem. Corsivo nel testo originale. Crivellari si rifà qui all'opera di Nicolini, Le questioni di diritto, Laurich, Napoli 1870.

67 Ibidem.

68 Ibidem. Corsivo mio.

${ }^{69}$ Ivi, p. 507 sg. Corsivo nel testo originale. 
punto Crivellari richiede la presenza di due ulteriori requisiti. Il primo è dato dal fatto che i mezzi alternativi «fossero realmente utili, cioè efficaci alla salvezza $\gg^{70}$. Il secondo è dato dal fatto «che il calcolo sopra questa utilità potesse essere istituito dallo stesso aggredito [...]. Il moderame deve sempre misurarsi secondo le ragionevoli opinioni di colui che si vide minacciato nella vita; non secondo ciò che con freddo calcolo e maturo esame si è conosciuto dal giudice ${ }^{71}$.

In sintesi: la difesa legittima è una scusante del comportamento in violazione della «legge dell'ordine», prevista in casi di necessità quasi «fisica», a tutela principalmente del diritto alla vita e all'incolumità fisica o personale dell'aggredito, che agisce a livello dell'imputabilità, negandola. Il caso centrale è quello della conservazione della vita o della esistenza, a cui si aggiunge poi come strumentale quello della conservazione della incolumità fisica. Gli altri casi di difesa, in particolare di difesa del pudore vengono coperti se e in quanto siano riconducibili al principio sottostante alla legittima difesa. In un apposito paragrafo finale, seguendo la tradizione del diritto comune, Crivellari si chiede se «la eccezione del moderame di incolpata tutela de[bba] essere limitata soltanto alla aggressione contro la vita propria o di altrui $>^{72}$. Sulla scorta di argomentazioni ricavate dal diritto romano e dal diritto naturale di Grozio e Pufendorf, Crivellari propende per l'allargamento dell'ambito della difesa, ricorrendo al concetto di «violenza»: «Quella necessità adunque che costituisce tutta la legittimità della difesa della vita, si impone con tutta la sua forza anche nella ipotesi di un attentato violento al pudore ${ }^{73}$.

Un indicatore della stretta connessione tra il concetto di violenza e quello della vita o dell'esistenza nel discorso sulla difesa legittima è dato dal caso che Crivellari discute immediatamente a seguire: l'uccisione del marito che intende costringere la moglie a compiere «un atto contro natura a sfogo della propria libidine». In questo caso Crivellari vuole riconoscere la esimente del moderame di incolpata tutela per la moglie. Dopo aver a lungo ricostruito con forti tinte morali il conflitto tra l'uomo e la donna uniti dal «contratto di matrimonio», e aver risolto in senso affermativo la questione della non imputabilità della «onesta fanciulla» che avesse ucciso il «marito reso bruto dal vizio» e che volesse «servirsi di lei come un mezzo per isfogare gli istinti animali $»^{74}$, Crivellari chiude la sua argomentazione in tal modo: «Questo modo di sciogliere la questione parmi conforme ai sommi principii del giure penale, e al rispetto che i legislatori ed i giudici devono avere per un diritto tanto prezioso quanto è prezioso il diritto all'esistenza, e non meno irreparabile della vita stessa; irreparabilis tamquam vita $>^{75}$.

70 Ivi, p. 508. Corsivo nel testo originale.

71 Ibidem. Corsivo nel testo originale.

72 Ivi, p. 515.

73 Ivi, p. 516. Corsivo nel testo originale.

74 Ibidem.

75 Ivi, p. 517. 
In tal modo Crivellari marca come decisivi requisiti di somiglianza tra l'onore (della donna) e la vita, accanto all'alto valore intrinseco ovvero alla «preziosità», l'ulteriore profilo della loro «irreparabilità» ovvero dell'impossibilità di 'riparare' alla loro perdita. Una tale concezione copre dal punto di vista argomentativo la disciplina del Codice Zanardelli. All'art. 49, che disciplina in via generale la legittima difesa come «reazione necessaria» nei confronti di una «violenza attuale e ingiusta» e quindi esclude in via principale la tutela dei beni patrimoniali, perché l'aggressione nei loro confronti non costituisce «violenza», corrisponde come norma speciale l'art. 376 che disciplina i casi tipici di «violenza» nei confronti dei beni patrimoniali ovvero di aggressioni ai beni patrimoniali che costituiscono anche una «violenza». Come Crivellari osserva, la «dottrina moderna», ovvero implicitamente le citate concezioni di Pessina, Carrara, Puccioni e Nicolini possono essere viste senza soluzione di continuità rispetto $\mathrm{al} \ll$ Diritto antico» ovvero all' istituto del «moderame di incolpata tutela» ${ }^{76}$.

\section{La crisi del concetto di legittima difesa come «moderamen inculpatae tutelae»}

Il paradigma del moderamen inculpatae tutelae alla base della disciplina del Codice Zanardelli comincia ben presto a vacillare.

\subsection{L'importanza di essere onesto (Fioretti)}

Nel 1886, cioè tre anni prima del completamento della lunga gestazione del Codice penale Zanardelli, Giulio Fioretti scrive una breve monografia che mette in discussione l'impianto della disciplina della legittima difesa prevista dal Codice penale sardo, ancora vigente, attaccando la concezione di Carrara, considerato all'epoca il più autorevole giurista penalista. Nell'Introduzione Fioretti posiziona il suo studio all'interno della concezione della Scuola positiva, nella scia di Lombroso, Ferri, Garofalo, in implicita contrapposizione con la 'Scuola classica' ovvero principalmente con Carrara ${ }^{77}$. Il suo obiettivo dichiarato è quello di «dimostrare come quella inconcepibile tenerezza della legge per il delinquente è spinta a tal segno, da favorirlo non soltanto nell'eccessiva mitigazione delle pene, ma anche, e con più flagrante assurdità, coi troppi ostacoli che si creano al privato nella difesa personale da un attacco violento e ingiusto alla propria

76 Simile a quella di Crivellari è sotto questo profilo la concezione di Francesco Saverio Arabia. Secondo Arabia la nuova disposizione «è quello che dicevasi prima moderamine inculpatae tutelae, o legittima difesa, tanto che meglio sarebbe stato di riprodurre l'antichissima definizione. Ma se ciò non si è fatto per un quasi sistema che pare si siano imposto $i$ compilatori del Nuovo Codice di allontanarsi per quanto si può dal linguaggio legale già ricevuto, credendo che così si aiuta l'intendimento dei giurati, l'articolo in sostanza riproduce il concetto dell'antica definizione» (F.S. Arabia, I principii del diritto penale applicati al codice italiano, Tip. della R. Università, Napoli 1891, p. 154).

77 G. Fioretti, Su la legittima difesa, studio di criminologia dell'avvocato Giulio Fioretti, Bocca, Torino 1886, p. 8. 
integrità fisica, morale ed economica $»^{78}$. Tale «aberrazione di sentimentalismo dottrinario ${ }^{79}$ sarebbe stata potenziata, ai fini della produzione di «tanti e gravi danni», dalla «deplorevole complicità» fornita dai «precedenti storici del giure penale e dell'evoluzione dei sentimenti morali dell'Europa civile $\gg^{80}$, in altre parole: da un lato dalla storia 'criminale' del diritto penale stesso, con il suo carico di palesi e gravi ingiustizie, e dall'altro dal progresso della civilizzazione europea. Nell'esporre la sua concezione della legittima difesa Fioretti procede fondamentalmente a una ricostruzione storica, analizzando lo sviluppo dell' istituto della legittima difesa dal diritto romano fino al suo tempo. Fioretti oppone al moderamen inculpatae tutelae del diritto canonico e alle idee astratte proprie dei «filosofi del diritto» e del diritto di ragione la tradizione del diritto romano in tema di legittima difesa, collegandola produttivamente alla nuova scienza giuridica tedesca, che nella seconda metà del XIX secolo pone la domanda circa la natura dogmatico-giuridica della legittima difesa: «La questione grossa sta nel determinare se la legittima difesa sia un diritto ovvero una scusa più o meno piena del reato» ${ }^{81}$.

Con collegamento a Rudolf von Jhering, il civilista tedesco autore tra l'altro del noto Der Kampf um's Recht, Fioretti scrive:

Chi non vede che la legittima difesa altro non è che una delle forme della lotta contro il delitto? Essa rappresenta quella parte del magistero sociale di repressione che può essere senza pericolo lasciata alla iniziativa privata. E pure è proprio questo concetto così semplice ed evidente dell' indole di questo istituto, che più raramente si fa strada a traverso le nebulose disquisizioni dei filosofi del diritto. Oggi ancora è la teorica individuale, atomistica della legittima difesa, quella universalmente imperante. Quando nelle teoriche di filosofia del diritto si trascura totalmente l'elemento sociale o utilitario, che dir si voglia, e tutte le costruzioni teoretiche si vogliono elevare coi soli materiali che può presentare la elucubrazione aprioristica delle ipotetiche facoltà individuali dell'uomo isolatamente considerato, la legittima difesa discende sempre al grado di mera scusante, e non è mai concepita come l'esercizio di un diritto ${ }^{82}$.

Un criterio importante e da non trascurare è per Fioretti quello dell'«ingiustizia dell'aggressione», che Fioretti fa valere contro l'estenuante 'iperdifferenziazione' dovuta al moderamen:

[...] tutto ciò che tende ad eliminare assieme al pericolo per l'aggredito, le forze criminose dell'aggressore, è fatto nell' interesse della società; chi respinge l'ingiusto aggressore compie un atto di giustizia sociale. La sua azione è esercizio di un diritto, non meno che la pena inflitta dall'autorità sociale [...]. Nel nostro

\footnotetext{
78 Ivi, p. 11.

79 Ibidem.

80 Ibidem.

81 Ivi, p. 46.

82 Ivi, p. 47.
} 
Codice [il Codice sardo del 1859] può questionarsi, se sia da concedersi la legittima difesa al ladro posto in pericolo di vita dal derubato, se la si debba concedere contro l'eccesso di difesa, o al drudo colto dal marito in flagrante adulterio. La difesa legittima è ridotta a una specie di conteggio tra aggredito e aggressore; ad ogni piccola quantità di eccesso da una parte corrisponde un po' di legittima difesa dall'altra. Tutte queste difficoltà scompaiono quando invece di considerarla come una causa dirimente l'imputabilità, la si considera come l'esercizio di un diritto. L'aggressione ingiusta ha fatto scomparire fin dal primo momento la possibilità dell'esistenza di questo diritto nell'aggressore; perché la società non può avere interesse a che un malfattore conservi la sua vita. $[\ldots]^{83}$.

Dopo aver tratteggiato in generale i contorni del diritto alla difesa legittima, Fioretti passa alla vexata quaestio della difesa dei beni. Essa sarà legittima qualora «il furto rappresenti una perdita sensibile per il proprietario». Un'esemplificazione è data dalla difesa del fondo da parte del contadino:

La pratica dimostra quanto sieno inutili le proibizioni della legge per le schioppettate tirate al tempo del raccolto contro coloro che si intromettono nei fondi allo scopo di rubarne i frutti. La proprietà rustica è molto più della proprietà mobiliare ed urbana esposta al furto, e bisogna necessariamente concedere al proprietario maggiori diritti per la difesa dei suoi beni [...]. Un contadino che tira una schioppettata a chi, malgrado l'avviso avutone, si ostina a voler penetrare nella proprietà altrui, non dimostra nessuna anomalia di carattere che possa autorizzarci a reputarlo un delinquente. Una simile facoltà si concede alle sentinelle, e talvolta, per motivi futilissimi, e con pericolo gravissimo dei passanti $[\ldots]^{84}$.

\subsection{La Cassazione e gli offendicula ovvero: il contributo della tecnica}

L'idea che il diritto alla vita, anche quello del ladro, abbia priorità assoluta rispetto al diritto di proprietà è sempre più difficile da accettare. La tecnica fornisce il suo contributo. Lo sviluppo di congegni meccanici per azionare 'automaticamente' armi da fuoco pone la giurisprudenza e quindi la dottrina dinanzi a una versione sofisticata del tradizionale caso dell'uccisione del 'ladro notturno' ovvero più precisamente a un suo slittamento: si tratta della questione della liceità o meno dell'uccisione del ladro mediante congegni meccanici ovvero offendicula. Questa infatti si può verificare anche nel caso in cui il proprietario o i suoi famigliari non si trovino in casa e sia quindi esclusa per definizione la connessione tra l'aggressione ai beni e l'incolumità fisica, tradizionalmente chiamata in causa come ratio delle fattispecie di cui all'art. 376. Per l'applicabilità dell'art. 376 anche a tal caso si pronuncia la Cassazione nel 1898 in un'impor-

\footnotetext{
83 Ivi, p. 81 , p. 87 sg. Corsivo nel testo originale.

84 Ivi, p. $90 \mathrm{sg}$.
} 
tante sentenza ${ }^{85}$, che apre una significativa breccia nel principio della necessaria connessione tra minaccia ai beni e minaccia all'incolumità della persona.

\section{L'attacco contro la «delinquenza e la malavita» e la legittima difesa}

\subsection{La legittima difesa dalla «malavita» ovvero dalla «gente abietta» (Manzini)}

I toni divengono sempre più accesi. Vincenzo Manzini tiene il 22 novembre 1910 una prolusione all'Università di Torino, pubblicata nel 1911 con il titolo La politica criminale e il problema della lotta contro la delinquenza e la malavita ${ }^{86}$, che segna il cambio di paradigma a favore di una politica del diritto penale di rara 'dedifferenziazione' ${ }^{87}$. Manzini indica programmaticamente la «difesa sociale contro la peggior delinquenza e la malavita $\gg$ come uno dei «più gravi e urgenti » problemi del tempo ${ }^{88}$. Per attuare tale difesa Manzini indica «mezzi immediati» e $\ll$ mezzi mediati ${ }^{89}$. Per $\ll$ mezzi mediati $\gg$ Manzini intende $\ll$ l'educazione popolare, la diffusione del benessere, la lotta contro l'alcoolismo ecc. ${ }^{90}$. Si tratta qui dei rimedi che cercano di lottare contro il crimine riconoscendone le cause sociali. Qui Manzini nega la competenza del diritto penale per tali interventi. Tali questioni andrebbero $\ll$ manifestamente $\gg$ oltre il suo $\ll$ campo ${ }^{91}$. Escluso

85 Corte di Cassazione, Udienza del 10 novembre 1897, Montalboldi, «La legge, Monitore giudiziario ed amministrativo del Regno d'Italia», I, 1898, p. 205 sg. In una nota a tale sentenza Alessandro Stoppato indebolisce ulteriormente il paradigma del moderamen inculpatae tutelae. Stoppato contrappone il diritto alla vita e il diritto di proprietà dei «cittadini» e dei «galantuomini» a quello dei «ladri», arrivando a ricondurre la proprietà aggredita al bene della vita, per il tramite del lavoro e quindi della vita incorporata nel bene prodotto. Vedi A. Stoppato, Il diritto del proprietario di apprestare nella sua casa mezzi per uccidere il ladro notturno, «La Cassazione unica», X, 11, 1898, p. 386 sg.; esemplarmente si veda ivi, p. 386: «È vero $[\ldots]$ che scade, nella proporzione giuridica, il dritto di proprietà in confronto di quello della vita, ma è pur vero che il primo non è se non che una esplicazione dell'altro».

86 V. Manzini, La politica criminale e il problema della lotta contro la delinquenza e la malavita, «Rivista penale», 73, 1911, p. 5 sgg.

87 Nella sua analisi della prolusione di Arturo Rocco all'Università di Sassari del 1910, pubblicata con il titolo Il problema e il metodo della scienza del diritto penale, Mario Sbriccoli, ricordando in una nota «l'egemonia accademica e politica» di Vincenzo Manzini nella prima metà del ventesimo secolo e sottolineando come il ruolo di Manzini «certo meriterebbe attenzione e studio», tematizza questa prolusione torinese del 1910. In essa vi sarebbe «molta più anticipazione e "promessa" di fascismo di quanta se ne possa vedere, specie se non si guarda bene, nella "politicità dell'apolitico" che si rimprovera - peraltro giustamente - a quella di Rocco». M. Sbriccoli, Caratteri originali e tratti permanenti del sistema penale italiano (1860-1990), in Storia d'Italia. Annali, vol. XIV. Legge diritto giustizia, a cura di L. Violante, Einaudi, Torino 1998, p. 485 sg., p. 524, nota 104. Cfr. qui A. Berardi, Vincenzo Manzini. Del metodo giuridico, Edizioni scientifiche italiane, Napoli 2003, in particolare p. $187 \mathrm{sg}$.

88 Manzini, La politica criminale, cit., p. 7.

89 Ivi, p. 8.

90 Ibidem.

91 Ibidem. 
in tal modo l'ambito del 'sociale', a Manzini resta l'ambito del 'penale' in senso stretto. Vengono quindi in considerazione quelli che Manzini chiama «mezzi immediati». Manzini distingue ulteriormente tra «mezzi privati»e e «mezzi pubblici». Per quel che concerne i primi, egli non fornisce un chiaro criterio di individuazione. Tuttavia possiamo capire che cosa Manzini intenda nel momento in cui consideriamo l'articolazione da lui operata. Manzini dice: $\ll[R]$ ispetto ai mezzi privati, l'effetto che si cerca può esser conseguito in parte mediante opportune norme giuridiche permissive; in parte, e assai meglio, mediante la rettificazione di alcune norme etiche $\gg^{92}$.

Abbiamo così da fare da un lato con l'introduzione ad hoc di specifici permessi in capo ai privati e dall'altro con la modifica della 'morale pubblica'. Manzini fornisce un solo esempio di modifica delle norme giuridiche permissive. E si tratta proprio delle norme sulla legittima difesa. Secondo Manzini le norme sulla legittima difesa del Codice Zanardelli potrebbero «sembrare di per sé sufficienti». Esse avrebbero la «potenzialità di tutela del galantuomo contro il malfattore ${ }^{93}$. Tale potenzialità verrebbe tuttavia vanificata sul piano processuale, in quanto mancherebbero «le opportune norme processuali integratrici»:

Voi sapete bensì di poter reagire violentemente contro l'ingiusto aggressore, ma conoscete anche a quante vessazioni processuali, a quante spese, e a che gravi pericoli giudiziari vi esporreste reagendo effettivamente. E questa previsione paralizza fatalmente, e talora letalmente, le oneste energie reattive, a tutto benefizio dei criminali, la cui audacia cresce alimentata dalla convinzione di non trovare resistenza ${ }^{94}$.

Manzini propone quindil'eliminazione dell'arresto preventivo di chi ha agito in legittima difesa e l'istituzione di una «speciale procedura istruttoria ${ }^{95}$ per la legittima difesa. Per quel che concerne il «campo etico», Manzini argomenta a favore di una mobilitazione della società con le armi contro la delinquenza:

Nel campo etico conviene poi dar opera a diffondere la persuasione dell'erroneità del concetto per cui si stima quasi vergognoso portare armi a propria difesa, $e$ la convinzione che l'uso delle armi contro gli aggressori non solo rappresenta l'esercizio di una facoltà, ma anche l'adempimento d'un dovere sociale, quale è certamente quello di contribuire a rintuzzare la temerarietà e la protervia dei malviventi, a intimidire e disperdere la malavita ${ }^{96}$.

L'aggredito viene fatto destinatario di un «dovere sociale» di difendersi con le armi, e in tal modo incorporato nella politica criminale dello Stato. Vengono quindi i «mezzi pubblici», che Manzini distingue ulteriormente tra «mezzi di

\footnotetext{
92 Ibidem.

93 Ibidem.

94 Ibidem.

95 Ibidem.

96 Ibidem.
} 
diritto penale»e «mezzi di polizia». In questo contesto mi limito a ricordare la durezza con la quale Manzini argomenta a favore dell' inasprimento delle pene ${ }^{97}$ nei «mezzi pubblici» e della reintroduzione della pena di morte ${ }^{98}$. Qui Manzini argomenta contrapponendo con forza due modi di pensare e strutturare il diritto penale. Da una parte vi sarebbe una concezione del diritto penale 'mite' e troppo favorevole ai delinquenti. Dall'altra vi sarebbe la concezione preferita da Manzini, una concezione che ricolloca i diritti degli 'onesti' al centro dell'attenzione del diritto penale:

Il nostro sistema penale, che del resto non ebbe mai completa attuazione, è non solo troppo mite, date le condizioni italiane, ma è altresì foggiato su modelli creati per popoli d'indole, di costumi, di disciplina diversi dal nostro. Esso si ispira inoltre a un criterio fondamentalmente erroneo, fatale petizione di principio su cui si erige tutta la sua complessa costruzione. Il suo spirito si adegua assai più alla psiche della gente colta e onesta che a quella dei malfattori: si è creduto che costoro sentano e soffrano moralmente al modo nostro, attribuendo così alla restrizione della libertà personale un valore, che la gente abietta o anche semplicemente la gente incolta e povera è ben lungi dall'attribuirle. A ciò si aggiunga una buona dose d'effeminato sentimentalismo a benefizio dei peggiori membri della società, e una valutazione troppo egualitaria, astratta e cieca dei così detti diritti della personalità individuale ${ }^{99}$.

E ancora, per chi potesse equivocare:

L'Italia si è presa il lusso, unica tra igrandi Stati, di appagare una lunga e generosa aspirazione della sua classe colta, nella quale la nobiltà della razza e l'antica civiltà ànno creato ripugnanze e sentimenti non avvertiti con pari intensità da popoli economicamente più progrediti, ma di civiltà più recente. L'abolizione della pena di morte, tranne che per i militari e i sudditi coloniali, fu, invero, l'omaggio del Governo italiano alla classe colta della nazione, non certo a quella, almeno intenzionalmente, che dimostra di partecipare così poco alle suddette ripugnanze e ai sentimenti della prima, da produrre ogni anno circa 10.000 criminali rei di gravi delitti violenti, dei quali circa 150 (condannati all'ergastolo o alla reclusione per $30 \mathrm{anni}$ ) candidati ipotetici all'estremo supplizio ${ }^{100}$.

Con una concezione così unilateralmente 'securitaria' e 'muscolare' è difficile stupirsi delle conseguenze tratte da Manzini nel prosieguo della sua argomen-

97 Ivi, p. 9.

98 Per una considerazione più ampia rinvio al mio Della violenza nel diritto penale fascista, cit., p. 70 sgg.

99 Manzini, La politica criminale, cit., p. 9.

${ }^{100}$ Ivi, p. 10. 
tazione, e cioè la proposta della reintroduzione della fustigazione ${ }^{101}$ nonché di misure di polizia a tempo indeterminato per i recidivi 'incorreggibili' ${ }^{102}$.

\subsection{La lotta alla delinquenza per mezzo della legittima difesa (Battaglini)}

La lotta alla 'criminalità' ovvero alla 'delinquenza' diviene momento centrale nella dogmatica sulla legittima difesa. Nel saggio pubblicato nel 1911, un anno dopo la prolusione di Manzini ${ }^{103}$, con il significativo titolo Il pericolo d'offesa nella legittima difesa, Battaglini colloca la legittima difesa al centro della politica criminale dello Stato: $\ll[F]$ inché non cesserà il reato, come negazione dell'armonia sociale, lottare contro la criminalità sarà sempre uno dei primi doveri e dello Stato e dei cittadini, in quanto la difesa pubblica e la difesa privata sono due grandi forze cooperanti nella lotta contro la criminalità ${ }^{104}$.

Battaglini mobilita difesa pubblica e difesa privata contro l'obiettivo comune: la «criminalità». Egli posiziona la «difesa privata» accanto alla «difesa pubblica $\gg$ organizzata dallo Stato, asservendola a essa. Mentre però la «lotta contro la criminalità $»$ per lo Stato costituisce l'esercizio di un «dovere giuridico», per i «privat $[\mathrm{i}] \gg$ costituisce l'esercizio di un «dovere etico-sociale $\gg$ ovvero un «dovere etico», che cioè è «privo della particolare imperatività del dovere giuridico ${ }^{105}$. Tale colorazione pubblicistica trasforma la legittima difesa da «diritto subiettivo» in capo al cittadino in «possibilità o autorizzazione giuridica riflessa $\gg$ in capo al «suddito $\gg$ in forza dell' $\ll$ obbligo $\gg$ per lo Stato «di non punire l'autodifensore ${ }^{106}$. In tal modo la legittima difesa diviene uno strumento per la mobilitazione contro la delinquenza ai fini di prevenzione dei reati ${ }^{107}$.

${ }^{101}$ Esemplarmente: «Negli uomini imbevuti delle idee della rivoluzione francese il solo nome di questa pena suol produrre uno scoppio di sdegno declamatorio; ma chi non è avvinto a pregiudizi filosofici o politici comprende che, se simili pene sono certamente un intollerabile affronto alla dignità della personalità individuale, lo sono in quanto codesta personalità sia quale viene presupposta dai filosofi e dai politici: non quale la vedono i penalisti, troppo spesso, nelle aule giudiziarie e nelle prigioni» (ivi, p. 11).

${ }^{102}$ Ivi, p. 10 sgg. Ampiamente sul punto il mio Della violenza nel diritto penale fascista, cit., p. 73 sgg.

${ }^{103}$ La priorità temporale spetta al saggio di Manzini, che viene tra l'altro espressamente citato da Battaglini. Cfr. G. Battaglini, Il pericolo d'offesa nella legittima difesa, «Studi e giudicati illustrativi del Codice penale italiano», 20, 1911, p. 147 sgg., nota a p. 153.

${ }^{104}$ Ivi, p. 147 sgg.

105 Ivi, p. 150.

${ }^{106}$ Ivi, p. 151. Ancora nel 1910 lo stesso Battaglini ricostruiva la legittima difesa come «diritto subiettivo di autodifesa» in capo al suddito e in rappresentanza dello Stato. Vedi G.Q. Battaglini, Le norme di diritto penale e i loro destinatari, Loescher, Roma 1910, p. 38. Vedi ampiamente il mio Della violenza nel diritto penale fascista, cit., p. $67 \mathrm{sg}$.

${ }^{107}$ Con riferimento a von Ferneck, Battaglini scrive: «Lo Stato, riconoscendo ai sudditi la possibilità di difendere con la propria forza i beni giuridici pericolanti, viene a rinforzare considerevolmente i motivi di astensione dal reato, contenuti dalle norme. La possibilità di 
Ma come avviene la prevenzione per mezzo della legittima difesa? Quali effetti ha la legittima difesa sui «delinquenti»? È una questione di conflitto tra le forze contrapposte. La forza della legittima difesa agisce a mo' di inibizione sul delinquente, andando ad influire positivamente a favore della società sul rapporto tra i motivi che si fronteggiano nell' $\ll$ individuo che delinque ${ }^{108}$. La legittima difesa collega la «lotta per il diritto» nella società alla «lotta» che si verifica 'all'interno dell'individuo'. Questo per quanto riguarda la teoria. Quanto alla pratica, ovvero al «funzionamento» della legittima difesa nella società italiana, Battaglini osserva criticamente che la legittima difesa $\ll[\ldots]$ nello stato del suo funzionamento attuale $[\ldots]$ non esercit[a] quel potere inibitorio contro i motivi criminali, che di essenza sua possiede $\gg^{109}$. In una prospettiva non dissimile da quella di Manzini, egli esorta a incoraggiare i cittadini all'«esercizio dell'autodifesa», senza che questi vengano spaventati dalla «prospettiva di pericoli giudiziari», dalle possibili ripercussioni dovute dall'esercizio dell'azione penale nei confronti delle vittime che si siano difese con vigore dai loro aggressori: $\ll \mathrm{Va}$ insomma tolta la timidezza dell'autodifesa e aumentata l'energia privata contro la delinquenza [...]. Bisogna educare gli onesti all'energia e all'attività, se si vuol combattere efficacemente la delinquenza $\gg^{110}$.

Riprendendo implicitamente il tema caro a Fioretti e soprattutto a Manzini ${ }^{111}$, Battaglini contrappone «gli onesti alla «delinquenza». È compito del diritto penale e soprattutto della legittima difesa «educare» la parte «onesta» della popolazione per la «lotta» contro la parte implicitamente 'disonesta' ovvero 'delinquente'. Corrispondentemente Battaglini propone, nella scia di Manzini, di abolire la carcerazione preventiva per chi «secondo ogni verosimiglianza» abbia agito in legittima difesa. Ma come fonda Battaglini il dovere etico-sociale dei sudditi di «combattere la criminalità» agendo in «autodifesa»? Battaglini si rifà qui alla massima 'tradizionale' di Machiavelli secondo la quale «il fine giustifica i mezzi» per far prevalere nei confronti del diritto alla vita dell'aggressore il fine del benessere sociale e della «elevazione della vita umana», da raggiungere per il mezzo della difesa anche mortale ${ }^{12}$. A questo movimento di affievolimento della tutela del diritto alla vita corrisponde un indebolimento dell'importante

autodifesa e l'autodifesa effettivamente esercitata operano una prevenzione contro il reato» (Battaglini, Il pericolo d'offesa, cit., p. 152).

108 «L'individuo che delinque è un individuo in cui i motivi della criminalità ànno preso il sopravvento sui motivi dell'armonia sociale. Ora, c'è un momento in cui la lotta nel suo spirito si combatte tra gli opposti motivi, e i motivi dell'armonia sociale stanno per essere vinti da quelli della criminalità. Una forza inibitrice si oppone a questi ultimi motivi, e li rende deboli nella lotta e soccombenti: è la rappresentazione delle conseguenze del torto. E in questa rappresentazione il pericolo d'incorrere nella pena dello Stato si associa a quello d'incorrere nella reazione privata. Pena dello Stato e reazione privata sono i due grandi contromotivi al reato» (ibidem; corsivo mio).

109 Ivi, p. 153.

${ }^{110}$ Ibidem.

${ }^{111}$ Ibidem.

${ }^{112}$ Ibidem. 
requisito di fattispecie dell'art. 49 del Codice Zanardelli della «violenza», ridotto a «pericolo di un' ingiusta offesa». Battaglini interpreta infatti il requisito della violenza smaterializzandone il contenuto 'fisico-materiale' e valorizzando così un nucleo dato dall' $\ll$ ingiusto danno» e dalla «ingiusta offesa ${ }^{113}$.

La concezione proposta da Battaglini permette di pensare come legittima la difesa di qualsiasi bene giuridico. Il dato normativo positivo è però chiaramente vincolante per Battaglini. Egli determina con riferimento a quali beni possa aversi una legittima difesa secondo il diritto italiano, escludendo espressamente la «difesa dei beni», salvo il caso in cui «all'attacco contro i beni sia connesso un pericolo per la persona». I casi di cui all'art. 376 vengono inoltre considerati da Battaglini come tassativi. Quanto alla nuova questione degli offendicula contro i ladri notturni, Battaglini ritiene coperta dall'art. 376 n. 2 la difesa mediante apparecchi automatici nei confronti del ladro che per entrare nella casa nottetempo scali, rompa ovvero provochi un incendio. Al di là di queste ipotesi tassative l'uccisione del ladro notturno che sia entrato senza «bisogno di rompere o di scalare» non sarebbe coperta dalla disposizione sulla legittima difesa e resterebbe punita ${ }^{114}$.

\section{II progetto Rocco del 1927: il diritto a uccidere in legittima difesa}

Nel 1921 viene presentato il progetto Ferri. La difesa legittima è disciplinata nel titolo II del libro I, dedicato alla disciplina de Il delinquente, al capo I Della responsabilità. Qui l'art. 19 recita con riferimento alla legittima difesa, senza mutamenti particolari rispetto alla disposizione generale dell'art. 49 del Codice Zanardelli: «Il fatto è giustificato, agli effetti penali, quando sia compiuto [...] per la necessità di difendere sé od altri da una violenza attuale ed ingiusta ${ }^{115}$.

Diverso è il caso del Codice Rocco, proposto nel 1927. In sei anni è successo molto. Nel 1922, un anno dopo la presentazione del progetto Ferri, le squadre fasciste marciano su Roma, prendendo di fatto il controllo dell'apparato statale italiano. Il Re rinuncia infatti a reprimere il colpo di stato e nomina Mussolini Capo del Governo. In pochi anni la «rivoluzione fascista» si compie. Nel 1924 viene ucciso il deputato Giacomo Matteotti, che aveva tra l'altro osato denunciare in Parlamento le violenze sistematiche operate dalle squadre fasciste durante la campagna elettorale a scopo di intimidazione. Mussolini si assume in un discorso al Parlamento la responsabilità politica dell'accaduto. Nel 1925 con un disegno di legge il Governo fascista chiede al Parlamento per delega la facoltà di emendare il Codice penale Zanardelli. Nel luglio 1925 viene picchia-

113 «Il legislatore $[\ldots]$ non parla di pericolo [...]. Ma necessità di respingere una violenza attuale e ingiusta non vuol dire altro che necessità di impedire un ingiusto danno, che attualmente ne sovrasta, ossia necessità di resistere e di opporsi al pericolo di un'ingiusta offesa imminente. Così deve intendersi l'art. 49 n. 2 cod. penale» (ivi, p. 155).

114 Ivi, p. 169.

${ }^{115}$ Progetto preliminare di Codice penale per i delitti (Libro I), «La scuola positiva. Rivista di diritto e procedura penale», 1, 1921, parte prima, p. 136. 
to con estrema durezza Amendola, «il più considerevole capo dell'opposizione parlamentare dopo l'eliminazione di Matteotti ${ }^{116}$. Amendola morirà per le conseguenze del pestaggio qualche mese dopo. Il 26 novembre 1925 viene promulgata la legge n. 2029 sulle associazioni segrete, che ha per oggetto principale il divieto di associazioni segrete e in particolare della Massoneria. Nella tornata di discussione alla Camera dei deputati del 28 novembre 1925 viene esaminato il disegno di legge Modificazioni ed aggiunte alla legge 13 giugno 1912, $n$. 555 , sulla cittadinanza, detta «legge sui fuoriusciti». Essa toglie la cittadinanza agli oppositori del regime all'estero e introduce il sequestro ed eventualmente la confisca dei loro beni. Qui il Ministro della giustizia Alfredo Rocco fa valere una sorta di 'difesa legittima' da parte dello Stato ovvero della Nazione nei confronti dei 'fuoriusciti':

È bene [...] togliere ogni dubbio in proposito: il cittadino postosi volontariamente fuori della compagine della Nazione, perde ogni titolo, ogni diritto, che gli possa derivare dalla Nazione (Vive approvazioni). Onorevoli colleghi, questa legge non è legge di persecuzione, è legge di difesa, e come tale bisogna considerarla, legge di difesa resa necessaria dal comportamento indegno di alcuni malvagi cittadini ${ }^{117}$.

Il disegno di legge viene approvato come legge n. 108 il 31 gennaio 1926. Il diritto penale risulta sempre più accessibile nei suoi punti cruciali al discorso della «necessità» e della «guerra». Il 17 dicembre 1925 durante la discussione al Senato del disegno di legge Delega al Governo del Re della facoltà di emendare il Codice penale, il Codice di procedura penale, le leggi sull'ordinamento giudiziario e di apportare nuove modificazioni e aggiunte al Codice civile, il ministro Alfredo Rocco tematizza la questione della reintroduzione della pena di morte, declinandola in termini di «necessità di difesa della società contro i delinquenti»:

[...] Bisogna anche rendersi conto delle supreme necessità di difesa della società contro i delinquenti; e purtroppo alcuni recenti fatti hanno dimostrato che la repressione penale non è quale dovrebbe essere, ed anche quale è reclamata dalla coscienza pubblica. Cito alcuni orribili delitti commessi su innocenti bambini a Roma e in altre città, per i quali, come per altre forme gravi di delinquenza di sangue, a molti sembra pena inadeguata perfino lo stesso ergastolo. In verità, è mia opinione che questo problema della pena suprema, che sembrava definitivamente risolto, sia da considerare ancora aperto. Ciò significa che in occasione della Riforma del Codice penale, si debba seriamente considerare se non convenga, come è avvenuto in altri Paesi, dopol'esperimento dell'abolizione, ripristinare la pena di morte $\gg^{118}$.

116 D. Mack Smith, Storia di cento anni di vita italiana visti attraverso il Corriere della Sera, Rizzoli, Milano 1978, p. 289.

${ }_{117}$ Alfredo Rocco, Discorsi parlamentari, il Mulino, Bologna 2005, p. 242. Corsivo mio.

118 Rocco, Discorsi parlamentari, cit., p. 264. Corsivo mio. In dettaglio sulla reintroduzione della pena di morte e sulla sua concreta applicazione vedi G. Tessitore, Fascismo e pena di morte. Consenso e informazione, Franco Angeli, Milano 2000, in particolare p. 93 sgg., p. 113 sgg. 
Dopo aver evidenziato le caratteristiche positive della pena di morte, Rocco si dedica a confutare quella che è «in verità, l'obbiezione veramente decisiva contro la pena capitale». Essa è secondo Arturo Rocco l'obiezione «desunta dal principio che l'uomo, il quale è fine, non può mai essere assunto al valore di mezzo». Dinanzi al principio di dignità umana Rocco si vede costretto a fare un cambio di marcia e ad argomentare filosoficamente o meglio: politicamente:

È questa una obiezione di indole teorica grave, e che non può essere evitata e sfuggita se non negando i principi su cui essa si basa, che sono i principi fondamentali della filosofia individualistica. L'inventore della formula "l'individuo che è fine, non può essere assunto al valore di mezzo" fu infatti Emanuele Kant. È dunque lo stesso pensiero liberale che si ricollega a questa dottrina. Era perciò assai difficile respingere, nel campo della legislazione, le conseguenze di un principio che si accettava senza contrasto nel campo della politica e della filosofia ${ }^{119}$.

Da bravo Kronjurist Rocco non scende nell'arena filosofica di Immanuel Kant e dei suoi allievi nel campo del diritto, $\mathrm{i}$ «freie Rechtslehrer», $\mathrm{i}$ «liberi maestri del diritto», cioè $\mathrm{i}$ «maestri del diritto» che in quanto liberi hanno il coraggio di riconoscere il diritto dettato dalla ragione e quindi di affermarne pubblicamente la vigenza ${ }^{120}$. Egli sa bene che la filosofia, che almeno a partire dalla modernità kantiana agisce $\ll$ nach dem Fuß der Gleichheit und Freiheit ${ }^{121}$, $\ll$ su di un piano di eguaglianza e libertà» con le facoltà sorelle con le quali si trova in conflitto almeno dal medioevo, e cioè la teologia, la medicina e - ecco il caso di Rocco e nostro - la giurisprudenza, gli toglierebbe senza alcuna pietà le belle penne di cui si è adornato con la vicinanza al potere ${ }^{122}$. Per risolvere la partita con $\mathrm{i}$ «filosofi» ovvero con $\mathrm{i}$ «liberi maestri del diritto» e capovolgere il paradigma liberale e democratico Rocco si rivolge alla politica tout court, nel senso

119 Rocco, Discorsi parlamentari, cit., p. 264 sg. Corsivo mio.

${ }^{120}$ Vedi qui I. Kant, Werkausgabe, vol. XI. Schriften zur Anthropologie, Geschichtsphilosophie, Politik und Pädagogik, 1, a cura di Wilhelm Weischedel, Suhrkamp, Frankfurt 1977, Der Streit der Fakultäten, p. 267 sgg., p. 362; tr. it. in Id., Scritti di filosofia della religione, a cura di Giuseppe Riconda, Mursia, Milano 1989, p. 229 sgg., p. 289.

${ }^{121}$ Ivi, p. 285; tr. it. cit., p. 241.

${ }^{122}$ Nel suo Streit der Fakultäten Kant scrive: «So bald eine dieser Fakultäten etwas als aus der Vernunft Entlehntes einzumischen wagt: so verletzt sie die Auktorität der durch sie gebietenden Regierung und kommt ins Gehege der philosophischen, die ihr alle glänzende von jener geborgte Federn ohne Verschonen abzieht, und mit ihr nach dem Fuß der Gleichheit und Freiheit verfährt» (ivi, p. 285). «Non appena una di queste Facoltà si azzarda a includere e a mescolare qualche cosa presa a prestito dalla ragione, allora essa offende l'autorità del Governo, che comanda per mezzo suo, ed entra nel recinto (Gehege) della Facoltà filosofica, la quale le strappa senza riguardo (ohne Verschonen) tutte le penne rilucenti, che essa ha al riparo del governo, e procede con essa sul piede di parità e di libertà» (tr. it. cit., p. 241; corsivi miei). Ho preferito, per la traduzione di Gehege, al termine riserva scelto da Riconda quello di recinto e, per la traduzione di ohne Verschonen, all'espressione senza risparmio impiegata da Riconda quella di senza riguardo. Cfr. il mio «Defensive Aufklärung». Lo Streit tra filosofia, politica e giurisprudenza nel Geheimer Artikel zum ewigen Frieden di Immanuel Kant, Libreria Alfani, Firenze 2018, p. 171 sgg. 
più forte del termine, con un'argomentazione che si articola in due passaggi. Il primo è il seguente:

[O]ggi la situazione è profondamente mutata. La rivoluzione intellettuale, che ha seguito la rivoluzione politica dell'ottobre 1922, ha rovesciato i termini del problema dei rapporti tra individuo e società, quali li poneva la dottrina liberale-democratica-socialista già dominante. Noi crediamo che l'individuo sia mezzo e non fine, che la società abbia fini suoi propri, che trascendono la vita dell'individuo, e a cui i fini individuali debbono subordinarsi ${ }^{123}$.

Per il caso che a qualcuno i conti non tornino ancora, Alfredo Rocco cala sul tavolo il suo atout, il massacro di centinaia di migliaia di soldati italiani durante la Prima guerra mondiale che gli italiani hanno ancora negli occhi, nel cuore e nell'anima, 'giustificato' in nome della necessità della guerra:

Questa ipotesi, che sembrava assurda alla filosofia dell'individualismo, che l'individuo sia assunto al valore di mezzo, noi la riconosciamo essere perfettamente possibile e normale, e come l'unica atta a spiegare certi grandi fenomeni della vita sociale, che la dottrina liberale non spiega che come assurde degenerazioni o mostruose pagine: ad esempio, la guerra. La guerra è infatti l'esempio più grandioso di sacrificio della vita degli individui ad un fine più alto, alle necessità storiche ed immanenti dello Stato e della Nazione. Ora, se questo sacrificio totale della vita si impone a uomini che nulla hanno da rimproverarsi, a cittadini esemplari, perché lo stesso sacrificio non potrà imporsi ai delinquenti, $i$ quali, certo, non meritano la stessa pietà e la stessa considerazione, per le necessità sociali dell'intimidazione e della eliminazione? Se è assunto al valore di mezzo il soldato, perché non potrà esserlo il reo ${ }^{124}$

In tal modo Alfredo Rocco apre la porta alla discussione sulla reintroduzione della pena di morte per il mezzo del nuovo Codice penale ${ }^{125}$. La 'dedifferenziazione' è notevole. La politica e la guerra colonizzano l'ambito del diritto. Il liberalismo come pensiero politico posto a fondamento del diritto penale viene letteralmente ribaltato: l'uomo non è più fine, ma semplicemente mezzo. Questo viene fondato dal punto di vista politico tramite il topos della «rivoluzione».

Nel 1926 viene approvato il testo unico di pubblica sicurezza. In esso vengono introdotte tra l'altro le nuove fattispecie penali dell'«espatrio abusivo» ovvero del tentativo di espatrio determinato «dal motivo politico ${ }^{126}$. Nel 1926 si compie il terzo attentato alla vita di Mussolini. La richiesta dell'introduzione della pena di morte a protezione del 'potere sovrano' è sempre più intensa.

123 Rocco, Discorsi parlamentari, cit., p. 265.

124 Ibidem.

125 «Io credo pertanto che questo problema della pena di morte non sia, come molti credono, esaurito, ma sia una questione ancora aperta che debba, con la dovuta ponderazione, discutersi e risolversi nella preparazione del nuovo Codice» (ibidem).

126 Si veda G. Neppi-Modona, M. Pellissero, La politica criminale durante il fascismo, in Storia d'Italia. Annali, vol. XII. La criminalità, a cura di L. Violante, Einaudi, Torino 1997, p. 757 sg., p. 773. 
Il periodico fascista «L'Impero» lancia una campagna di stampa chiedendo a importanti giuristi di pronunciarsi sulla legittimità o meno della pena di morte: Arturo Rocco, Vincenzo Manzini, Garofalo e altri si esprimono con vari argomenti a favore ${ }^{127}$. In questo contesto può essere considerata come paradigmatica del nuovo clima giuspenalistico l'opinione di Arturo Rocco. Nel suo articolo su «L'Impero» del 7 ottobre 1926 Rocco sottolinea, in modo non dissimile dal fratello Alfredo, come il fondamento razionale della pena di morte sia la necessità. Dopo aver citato numerosi esempi nella storia recente di ordinamenti giuridici che, dopo aver soppresso la pena di morte, l'hanno reintrodotta e sostenuto che «il movimento favorevole al ristabilimento della pena capitale in Italia s sarebbe «tutt'altro che recente» e risalirebbe all'uccisione del Re (il «nefando eccidio di Monza») nel 1900, Arturo Rocco fa valere contro le ragioni della filosofia e del diritto le ragioni della storia e quelle della ragion politica. Egli osserva:

Ma la pena di morte non ha solo per sé il suffragio della storia. Essa ha anche il suffragio della ragione. Il problema della pena capitale, infatti, non è un problema filosofico o un problema giuridico che possa essere risolto - come spesso si è tentato di fare - su la base di ragionamenti teorici e metafisici e di deduzioni logiche astratte e aprioristiche. Esso è un problema pratico, un problema di necessità sociale e politica. Necessità dell'estremo supplizio per la conservazione e la difesa della Nazione e dello Stato e insufficienza, a tal fine, delle altre pene ${ }^{128}$.

A quali condizioni è da ricondurre tale necessità? Qui la risposta di Arturo Rocco è chiara:

Questa necessità è essenzialmente contingente e variabile: muta da luogo a luogo e da tempo a tempo: varia da Stato a Stato e da momento a momento storico in uno stesso Stato. Essa può cessare e rinascere e poi morire e rivivere ancora [...]. Questa necessità è avvertita sopra tutto dall'oscuro istinto della razza e negli strati più profondi della coscienza nazionale. E questa necessità si sente, più assai che non si dimostri ${ }^{129}$.

Se la necessità, similmente a un essere dalle molte vite, vive, muore e rinasce, allora da dove viene? Chi pone la necessità? Chile dona la vita e gliela toglie successivamente? E soprattutto: che cosa sonol'«oscuro istinto della razza» e gli «strati più profondi della coscienza nazionale» che avvertono o meglio: sentono la necessità? E ancora: in che relazione si pone tale necessità con lo Stato? Contro una siffatta necessità sono ben poca cosa i dati forniti dalla «moderna deità statistica» ${ }^{130}$,

${ }^{127}$ Si vedano qui I. Mereu, La morte come pena, Donzelli, Roma 2000, p. 196 sgg.; Tessitore, Fascismo, cit., p. 153 sgg.; Tessitore parla di «colpevole agnosticismo»e «servilismo» da parte della dogmatica giuridica italiana (ivi, p. 153, p. 156, con riferimento a Enrico Ferri).

${ }^{128}$ Arturo Rocco, Sul ripristino della pena di morte, «L'Impero», 7 ottobre 1926, ristampato in Id., Opere giuridiche, vol. III. Scritti giuridici vari, Foro italiano, Roma 1933, p. 545, p. 549 sg. Corsivo mio.

${ }^{129}$ Ivi, p. 550.

${ }^{130}$ Ibidem. 
per non parlare delle «elucubrazioni metafisiche e dialettiche» ${ }^{131}$ dei filosofi sulla liceità o meno della pena di morte. Le argomentazioni basate sulla religione, sulla morale, sull'umanità, civiltà, giustizia e sul diritto naturale vengono escluse dal campo discorsivo. Questo viene dominato dalla «necessità sociale e politica»:

No. La questione è tutta nel vedere se in un dato Stato, in un dato momento storico, la coscienza pubblica senta ed avverta, almeno per certi più gravi delitti, la suprema necessità sociale e politica della pena capitale. La "giustizia" della pena di morte sta tutta nella sua variabile necessità, anzi, nella variabile coscienza collettiva della sua necessità ${ }^{132}$.

Dopo aver posizionato la sua concezione nella scia del «tutto scorre» di Eraclito, secondo il quale «la sola realtà sta[rebbe] nel flusso perenne del mutamento», Arturo Rocco ricorda come non vi sia la «giustizia» ma l'«opinione della giustizia», riconducibile alla volontà della maggioranza ${ }^{133}$. Egli si ricollega implicitamente a quanto aveva già sostenuto l'anno precedente in Parlamento il fratello Alfredo, che aveva sviluppato un simile argomento a fortior $i^{134}$, paragonando la posizione del condannato a morte a quella del soldato caduto in battaglia:

Del resto, perché mai la coscienza sociale dovrebbe turbarsi di fronte al necessario sacrificio della vita dei delinquenti, se essa non si turba di fronte al necessario sacrificio della vita degli uomini onesti? Perché mai, nei casi di guerra esterna o di guerra civile e in ogni altro "stato di necessità" individuale e sociale, dovrebbe essere socialmente consentito di imporre ai cittadini innocenti il dovere giuridico di morire nell'interesse della Patria, e dovrebbe ritenersi, invece, socialmente illecito e riprovevole imporre quella stessa obligatio moriendi a criminali autori di delitti gravissimi, - per giunta, con la formale garanzia di un giudizio legale - quando essa sia richiesta dalle indispensabili necessità di vita e di difesa dello Stato contro il pericolo sociale della delinquenza? Deve, dunque, la superstizione di un falso sentimentalismo, prevalere su le necessità di vita di una Nazione ${ }^{135}$ ?

«Alea jacta est». Le sorti del ('naturalmente' falso) «sentimentalismo» dei vari filosofi e giuristi-filosofi, che a vario titolo, rifacendosi (più che al Kant della difesa della dignità umana) al Beccaria critico della pena di morte, abbiano voluto ingenuamente e astrattamente perorare le ragioni dei delinquenti sono ampiamente segnate. Se la «vita innocente» viene sacrificata, a più forte ragione si sacrificherà la «vita colpevole». La necessità ovvero più specificatamente la necessità di vita dello Stato ovvero della Nazione prevale 'necessariamente' sul diritto alla vita del 'delinquente' condannato a morte. Ma c'è di più. Ora a

\footnotetext{
131 Ivi, p. 551.

132 Ibidem.

133 Ibidem.

134 Vedi sopra in questo testo.

135 Ivi, p. 551 sgg. Corsivo mio.
} 
cogliere con sicurezza la «coscienza giuridica del popolo italiano», il Volksgeist, non sono certo chiamati i filosofi à la Kant e nemmeno i giuristi à la Savigny, ma direttamente il Governo e il Parlamento. Infatti Rocco in chiusura del suo articolo teorizza un vero e proprio monopolio della politica a scapito della scienza del diritto in tema di pena di morte:

Quanto ai casi di applicazione della pena di morte (se debba essa limitarsi ai soli e più gravi delitti politici o ai soli e più atroci delitti comuni o estendersi agli unie agli altri insieme e a quali fra essi) e così pure quanto al modo di esecuzione della pena capitale, all'organo giudiziale cui deve esserne deferita l'applicazione, alle forme del procedimento e del giudizio e via dicendo, sono questioni particolari di politica legislativa penale che debbono essere riservate, io penso, al senno politico del Governo e del Parlamento. I quali sapranno — anche questa volta — rendersi interpreti sicuri e fedeli della coscienza giuridica della Nazione italiana ${ }^{136}$.

Con il solo estremamente vago limite implicito dell'applicazione ai più gravi delitti, politici o comuni, viene qui impiegato il principio «necessità non ha legge». A decidere della conformazione legale, della legge della pena di morte, sia dal punto di vista del diritto sostanziale che dal punto di vista del diritto processuale, sono chiamati solo «Governo e Parlamento» come «interpreti [...] della coscienza giuridica della Nazione italiana». In tal modo la necessità sociale $\mathrm{e}$ politica egemonizza il campo del diritto: si fa necessità giuridica.

Il 9 novembre 1926 Mussolini presenta alla Camera il progetto di legge chiamato «Provvedimenti per la difesa dello Stato». Esso verrà approvato il 25 novembre 1926 e pubblicato nella Gazzetta Ufficiale 6 dicembre 1926, n. 281. Viene reintrodotto un ampio crimen laesae maiestatis per la durata di cinque anni. L'intenzione è quella di combattere l'opposizione politica, ridotta a 'criminalità'. A conoscere di tali reati invece della Corte d'Assise viene istituito il Tribunale speciale per la difesa dello Stato, con una composizione a carattere prevalentemente militare o paramilitare ${ }^{137}$. I membri sono di nomina del Ministro della guerra. Dal 1931 verranno nominati dal Capo del Governo ${ }^{138}$. In tal modo viene vanificato il principio di separazione tra i poteri dello Stato. Predominano i tratti di una giustizia politico-militare ${ }^{139}$. Il Tribunale arriverà a pronunciare 42 condanne a morte, di cui 31 verranno eseguite ${ }^{140}$.

Un anno dopo, nel 1927, cinque anni dopo la presa del potere da parte del regime fascista, viene presentato il progetto preliminare di Codice penale ${ }^{141}$.

\footnotetext{
${ }^{136}$ Ivi, p. 552.

${ }^{137}$ Si veda qui Neppi-Modona, Pellissero, La politica, cit., p. 770 sgg.

${ }^{138}$ Ivi, p. 772 sgg.

139 Ibidem: «Giustizia politica che opera con strumenti di carattere militare».

${ }^{140}$ M. Sbriccoli, Le mani nella pasta e gli occhi al cielo. La penalistica italiana negli anni del fascismo, «Quaderni fiorentini per la storia del pensiero giuridico moderno», 28, 1999, p. 834 sgg., p. 835.

${ }^{141}$ Progetto preliminare di un nuovo codice penale, Roma, ottobre 1927.
} 
Questa volta tocca alle condizioni di legittimità della 'difesa' violenta non da parte dello Stato, ma da parte dei privati. La legittima difesa è regolata all'art. 54: «Non è punibile colui che ha commesso il fatto per esservi stato costretto dalla necessità di difendere un diritto proprio o altrui contro il pericolo attuale di un'offesa grave e ingiusta».

Lo spostamento rispetto alla formulazione del Codice Zanardelli è notevole. Viene recepita la concezione di Battaglini ${ }^{142}$. Il requisito della 'violenza attuale e ingiusta', che escludeva l'aggressione ai beni, viene sostituito dal requisito del 'pericolo attuale di un' offesa grave e ingiusta'. L'ambito dell'aggressione viene in tal modo ampliato. Ora il tipo di diritti aggrediti non è più rilevante. Vita, integrità fisica, onore, beni ricadono tutti sotto la previsione del nuovo articolo in quanto «diritti» sui quali incombe il «pericolo attuale di un'offesa grave e ingiusta». Unico residuo dell'attenzione ai beni giuridici in conflitto è la predicazione dell'offesa come «grave».

\section{Irritazioni e 'resistenze'}

Nei confronti della disposizione proposta si articola una certa 'resistenza' nel corso della discussione che segue il progetto Rocco.

\subsection{Magistratura, università e ordini professionali}

Innanzitutto sono da considerare le critiche svolte al progetto nell'ambito della discussione fatta partire e poi recepita in forma di volume dal ministero stesso. Si tratta delle indicazioni provenienti dalla magistratura, dalle università e dagli ordini degli avvocati, raccolte sinteticamente nei lavori preparatori del Codice penale e del Codice di procedura penale editi dal Ministero di giustizia $^{143}$. Esse sono indicazioni prevalentemente negative. Per ragioni di spazio mi limiterò a seguire ad analizzare solo il dissenso della Corte di Cassazione ${ }^{144}$.

142 Vedi sopra $s u b 4.2$.

143 Ministero della giustizia e degli affari di culto, Lavori preparatori del codice penale e del codice di procedura penale, vol. III. Osservazioni e proposte sul progetto preliminare di un nuovo codice penale, parte I. Art. 1-80, Tipografia delle Mantellate, Roma 1928.

144 Per le relazioni e i pareri delle varie Corti di Appello e della Procura generale di Palermo, delle Università e delle Commissioni reali e sindacali degli avvocati e procuratori si veda ivi, p. 394 sgg., p. 396 sgg. Tra i pareri delle Corti d'Appello solo quello della Corte d'Appello di Ancona concorda con il Progetto, seppure intervenendo a concretizzare «in via preventiva $\gg$ l'espressione vaga dell'«offesa grave e ingiusta $\gg$. Tutti gli altri, con maggiore o minor decisione sono critici nei confronti della riforma proposta. I pareri in questione sono i pareri della Corte d'Appello dell'Aquila, di Bari, Bologna, Catania, Firenze, Messina, Milano, Napoli, Palermo, Potenza, Trieste e della Procura generale di Palermo. Cfr. in dettaglio ivi, p. 396 sgg. Diverso è il caso dell'Università e delle Commissioni reali e sindacali degli avvocati e dei procuratori, che si dimostrano meno compatte rispetto alla magistratura nella critica del progetto di legge del Governo. In particolare, delle nove università i cui pareri vengono raccolti dal Ministero della giustizia e degli affari di culto ben tre danno parere senz'altro positivo (Università di Bari, Padova, Pavia), quattro danno parere senz'altro ne- 
Nelle sue osservazioni, approvate nell'assemblea plenaria del 21 dicembre $1927^{145}$, il relatore, il consigliere Marongiu, esordisce sottolineando come la norma in questione abbia sotto il profilo pratico «importanza di gran lunga superiore a quella di ogni altra più discussa norma ${ }^{146}$. Questo dipenderebbe dal fatto che tale norma è «destinata alla più larga applicazione». Marongiu riconnette la nuova disposizione a quella altrettanto nuova e da lui egualmente criticata della scriminante in forza dell'esercizio del diritto, attaccandole entrambe sotto il profilo della mancata differenziazione tra i beni giuridici protetti: «Tanto nell'una, quanto nell'altra norma, nessuna limitazione è contenuta in ordine alla natura del diritto da esercitare o da difendere: il concetto di necessità è bensì una delle limitazioni alla facoltà di difesa, ma essa si riferisce ugualmente a qualsiasi diritto ${ }^{147}$.

Un'analoga preoccupazione lo porta poi a leggere sistematicamente le due disposizioni in ulteriore connessione con quella sul delitto di ragion fattasi di cui agli artt. 399 e 400 del progetto. Secondo Marongiu l'interpretazione di tali norme porterebbe «facilmente all'ammissione della difesa privata per qualsiasi diritto offeso $\gg{ }^{148}$. A questo punto l'argomentazione di Marongiu si sviluppa espressamente su due piani: quello filosofico e quello giuridico. Accogliere una tale concezione normativa significherebbe fare «un salto indietro, fino ad accogliere concezioni antiquate, come quella del famoso contratto sociale». Qui Marongiu fa una ricostruzione non priva di audacia del pensiero kantiano e della sua ricezione:

Dopo che il Kant, raccogliendo dalla coscienza popolare una verità che ben si può dire innata nell'uomo, sentenziò che necessità non ha legge (frase terribile, sotto il manto della quale venne scatenato un conflitto mondiale), i seguaci del grande filosofo, per dare un contenuto pratico alla teoria del maestro, l'hanno amalgamata con quella del contratto sociale; e, cioè, avendo il cittadino delegato i suoi poteri allo Stato, questo è tenuto a difenderlo, sempre ed in ogni caso d'ingiusta lesione dei suoi diritti $\gg^{149}$.

gativo (Università di Bologna, Macerata, Napoli e Perugia), mentre le altre due (Università cattolica del Sacro Cuore di Milano e Università di Urbino) si collocano, con diverse sfumature, in una posizione intermedia. Cfr. ivi, p. 401 sgg. e p. 407 sgg.

${ }^{145}$ La relazione della Cassazione viene pubblicata per esteso nel vol. XXXIV (IV della 4. Serie) del 1928 della Giustizia penale nonché, assieme ai pareri delle Corti d'Appello, degli Ordini degli avvocati e delle Università, a cura del Ministero della giustizia e degli affari del culto nei Lavori preparatori del Codice penale e del codice di procedura penale, articolo per articolo. Di seguito si citerà da quest'ultima versione.

${ }^{146}$ Ministero della giustizia e degli affari di culto, Osservazioni, cit., p. 394.

147 Ibidem.

${ }^{148}$ Ivi, p. 395.

${ }^{149}$ Ibidem. Corsivo nel testo originale. In realtà Kant nella Metafisica dei costumi afferma sì che «Not kein Gebot [hat] (necessitas non habet legem)», ma aggiunge immediatamente che «gleichwohl kann es keine Not geben, welche, wass unrecht ist, gesetzmäßig machte», «allo stesso tempo non vi può essere alcuna necessità che sia in grado di rendere conforme a legge ciò che è illecito», considerando così il «Notrecht», lo «ius necessitatis», un «vermeinte [s] Recht», un «preteso diritto», e quindi non un diritto «in enger Bedeutung», «in senso stretto». Vedi I. Kant, Werkausgabe, vol. VIII. Die Metaphysik der Sitten, a cura di Wilhelm 
Qualora tale obbligo non venisse adempiuto dallo Stato, l'iniziativa tornerebbe al cittadino: $«[\mathrm{C}]$ ome avviene nei quotidiani contratti della vita comune, se lo Stato, per qualsiasi motivo, manca all'obbligo suo, il cittadino riacquista la sua completa libertà d'azione e, riprendendo l'esercizio dei poteri che aveva delegati, resta autorizzato a difendersi da sé, sempre che un suo diritto venga leso $\gg^{150}$.

A questo punto Marongiu fa uno scarto nella sua argomentazione: «Ma bando alla filosofia ed alle fisime del contratto sociale, che non è roba per i nostri giorni, soprattutto imperante il Fascismo, e restiamo nel campo giuridico» ${ }^{151}$.

In tal modo viene in primo luogo respinto l'argomento di chi giustifica l'ampliamento della legittima difesa individuando come motore decisivo di tale sviluppo nella dogmatica penalistica la dottrina del contratto sociale (e della sua violazione con l'aggressione ingiusta). Questa dottrina viene descritta come una dottrina di «fisime», di sottigliezze non necessarie e sofistiche in senso deteriore. Dall'altra parte, e soprattutto, viene presa la distanza in generale rispetto al modo di argomentare filosofico, facendo valere come unico campo argomentativo quello giuridico, ricavato per negazione rispetto a quello filosofico. Il diritto qui è il risultato dell'esclusione dell'argomentare filosofico e dell'argomentare facendo leva sul contratto sociale dal campo giuridico. A rafforzare i due argomenti è chiamato «l'impero del Fascismo». La Cassazione riformula ora il problema, facendo valere contro la 'deduzione' della legittima difesa anche a tutela di qualsiasi diritto o bene, quindi anche a tutela della proprietà in forza della violazione del contratto sociale, il monopolio legittimo della violenza da parte dello Stato:

La questione è tutta qui: di fronte alla nuova concezione di uno Stato, consapevole della sua autorità e della forza, alla quale concezione noi abbiamo fatto omaggio, come si può conciliare l'inopinata abdicazione dei suoi più gelosi poteri al cittadino, sino al punto da concedere libero corso all'esercizio della difesa privata per ogni e qualsiasi diritto? Di fronte alla necessità è mestieri inchinarsi; ma questa sia intesa entro la limitata cerchia della difesa personale, oltre la quale si va verso l'anarchia ${ }^{152}$.

In dettaglio: in un primo passo viene riconosciuta implicitamente l'autorità della nuova concezione dello Stato fascista, ricordando e implicitamente facendo valere «l'omaggio» fattole e sottolineando come tale concezione non sia compatibile con «l'inopinata abdicazione» dei «più gelosi poteri» dello Stato stesso al cittadino. In altri termini: come farà ad accettare il nuovo Stato (fascista), che si afferma forte e vigoroso, un infiacchimento e indebolimento delle sue prerogative a scapito dei sudditi? In un secondo passo la Cassazione concretizza in termini di politica penale la disciplina della legittima difesa. Da un

Weischedel, Suhrkamp, Frankfurt am Main 1977, pp. 341 e 343, tr. it. e note a cura di G. Vidari, La metafisica dei costumi, Laterza, Bari 2006, p. 40 sg. e 38.

${ }^{150}$ Ministero della giustizia e degli affari di culto, Osservazioni, cit., p. 395.

${ }^{151}$ Ibidem.

152 Ibidem. Corsivo mio. 
lato viene riconosciuto che «è mestieri inchinarsi alla necessità». La metafora dell'inchino permette così di riagganciarsi discorsivamente all'omaggio' già effettuato dalla Cassazione al fascismo, cercando di veicolare e prolungare gli effetti positivi dell'assoggettamento e riconoscimento dell'autorità dello stesso, con riferimento alla «necessità $\gg$.

Tramite la polisemia del concetto di «necessità», che richiama la necessità nella legittima difesa come la necessità della guerra e del fascismo, si ricollegano implicitamente l'omaggio della Cassazione al fascismo e ai suoi principi e l'omaggio ovvero l'inchino della Cassazione alla 'necessità' della regolamentazione della legittima difesa proposta dal fascismo. Tale ricostruzione è ulteriormente corroborata se si accosta il passaggio sopra ricordato a due ulteriori passaggi della relazione della Cassazione. Nell'apertura della sua relazione, la Cassazione afferma:

Il Supremo Collegio [...] non intende discutere i principi informatori della nuova grande opera legislativa: ne prende atto senz'altro con quella devota disciplina che è meritatamente dovuta agli atti del Governo Nazionale. Se i principi stessi, come d'altronde è evidente, siano quelli che meglio rispondano alle esigenze del profondo radicale mutamento dell'anima italiana, solo al Governo proponente è dato di decidere ${ }^{153}$.

Passando poi alla considerazione della nuova disciplina delle pene, ovvero all'introduzione della pena di morte, facendo espresso riferimento alla sua premessa, la Cassazione osserva: «L'innovazione più importante è quella che riguarda la pena di morte, a proposito della quale non è possibile dire argomento pro o contro che non sia stato detto. Si tratta d'uno dei capisaldi innovatori del progetto, che, giusta la premessa a queste modeste osservazioni, non si discutono ${ }^{154}$.

Alla necessità del fascismo, della difesa del fascismo con le leggi eccezionali, della reintroduzione della pena di morte, la Cassazione si è 'inchinata' e 'si inchina' di nuovo. Questi punti «non si discutono». Dall'altro lato, tale omaggio, tale 'inchinarsi', ha però dei limiti. Andare oltre i limiti del moderamen inculpatae tutelae dato tradizionalmente dall' incolumità personale porterebbe alla rottura del monopolio della forza da parte del fascismo e al ritorno della violenza tra i 'cittadini', reintrodurrebbe sistematicamente la violenza da poco bandita tramite l'instaurazione dell' ordine' fascista contro l'anarchia ovvero implicitamente: anche contro il 'disordine comunista'. La Cassazione ricorda inoltre che tale concezione vanta, oltre alla conformità con $\mathrm{i}$ «principi del fascismo», la conformità «al concetto tradizionale della dottrina italiana». La conclusione assai netta chiede il mantenimento della formula dello Zanardelli: «Il nostro dissenso pertanto è assoluto: più ne appaga la formula del codice vigente, che lo stesso Progetto Ferri aveva sostanzialmente rispettata [...]. Tanto è intuitivo ed

\footnotetext{
153 Ivi, p. 7.

${ }^{154}$ Ivi, p. 227 sg.
} 
evidente il grave pericolo, ch'è insito nella combattuta norma, che ben ci possiamo astenere da ogni ulteriore dimostrazione al riguardo $\gg^{155}$.

\subsection{Lo scontro in commissione ministeriale}

Critiche incontra il progetto di Alfredo Rocco anche nella commissione ministeriale incaricata di dare parere sul progetto. Nella discussione del 16 marzo 1928 si apre un vero e proprio 'fuoco di sbarramento' contro la riforma della legittima difesa. Subito dopo aver dato lettura del testo dell'art. 54 del progetto, il presidente Appiani comunica che il commissario De Nicola, che è assente, chiede la limitazione della legittima difesa «alla sola integrità personale ${ }^{156}$. Sempre De Nicola chiede «altresì di sostituire, alla parola "offesa" la parola "danno", che è fondamentale dell' istituto», ricordando infine l'opposizione all'ampliamento manifestata da «molte Corti di Appello» nonché dalla Cassazione, le quali «propongono il ritorno dell'antica formula, trovando troppo ampia la nuova ${ }^{157}$. Subito a seguire il commissario Longhi chiede da un lato che si continui a distinguere in tema di legittima difesa a seconda dei beni aggrediti ${ }^{158}$, trovando «eccessivamente allargato [...] il concetto di legittima difesa»; dall'altro lato Longhi vede una restrizione non giustificata della misura della legittima difesa data dal requisito del pericolo ${ }^{159}$. Egli chiede il mantenimento della formula dell'art. 49 del Codice Zanardelli. Non solo. Longhi propone addirittura di aggiungere una clausola di 'inevitabilità' della «violenza attuale e ingiusta» da respingere ${ }^{160}$, motivando tale proposta con la notevole frequenza di casi di difesa evidentemente sproporzionati, paradigmaticamente: l'uccisione da parte del contadino di chi cerchi di rubargli dei grappoli d'uva ${ }^{161}$.

Contro l'osservazione di Gismondi, secondo il quale in tal caso si applicherebbe la disciplina dell'eccesso colposo, Longhi torna sulle proprie parole e

155 Ivi, p. 396.

${ }^{156}$ Ministero della giustizia e degli affari di culto, Lavori preparatori del codice penale e del codice di procedura penale, vol. IV. Atti della Commissione Ministeriale incaricata di dare parere sul progetto preliminare di un nuovo codice penale, parte II, Verbale n. 13 del 16 marzo 1928, Tipografia delle Mantellate, Roma 1929, p. 158 gg., p. 162.

157 Ivi, p. $162 \mathrm{sg}$.

158 «Nota che nel Codice vigente la difesa della proprietà è permessa, ma solo entro determinati limiti. Ma del resto, è il caso di equiparare, nella misura della difesa, tutti i beni? L'oratore crede di no» (ivi, p. 163).

159 «Perché pericolo? A chi sta per dare un pugno si risponde anticipando egual pugno, senza che si ricorra all'accertamento di una situazione, che si esagera, quando la si vuole raffigurare in un pericolo» (ibidem; corsivo nel testo originale).

$160 \ll$ È pertanto d'avviso che si debba sopprimere la parola "pericolo" e tornare alla formula della "violenza attuale ed ingiusta". Inoltre si dovrebbe aggiungere: "che non si poteva altrimenti evitare” $\gg$ (ibidem).

$161 \ll$ È purtroppo assai frequente il fatto del campiere che, per difendere i propri grappoli d'uva, spara contro i ladri e li uccide. E quei grappoli d'uva non meritano, certo, così energica difesa» (ibidem). 
'aggiusta il tiro', aggiungendo al requisito della 'inevitabilità' quello veramente decisivo della 'proporzionalità'. Egli replica a Gismondi che non si avrebbe l'eccesso colposo nel momento in cui «si dimostrasse che i grappoli erano in pericolo e che, per tutelare questa proprietà era necessario quel mezzo $[. ..] \gg$. Un tale risultato interpretativo verrebbe scongiurato solamente nel caso in cui si decidesse $\ll[\ldots]$ come si augura, $[\mathrm{di}]$ precisare il concetto di necessità, in guisa che in esso si intenda incluso, non soltanto il concetto d'inevitabilità, ma pure quello di proporzionalità $\gg^{162}$. A dar man forte a De Nicola e Longhi si aggiunge Gregoraci. Anche per Gregoraci si sta andando troppo oltre. Egli cala sul tavolo una nuova e importante carta: quella degli interpreti della legge. Non solo i giurati, ma gli stessi magistrati tenderebbero già a interpretare l'attuale normativa sulla legittima difesa con troppo favor nei confronti dell'aggredito ${ }^{163}$. Gregoraci ricorda inoltre l'impressionante omogeneità del sentire giuridico mostrata dai partecipanti a un concorso di magistratura, i quali avrebbero quasi tutti risposto negativamente al quesito se vi fosse un obbligo a sottrarsi alla situazione di pericolo data dall'aggressione ingiusta ${ }^{164}$. In altri termini: se già gli interpreti allo stato attuale vedono un «no duty to retreat», allora va senz'altro riflettuto bene prima di spostare ulteriormente il pendolo della bilancia dalla parte dell'aggredito. Gregoraci chiede quindi che si consenta «solo la difesa dell'integrità personale, o tutt'al più di beni attinenti alla persona, come ad esempio il pudore, ma non già [de] gli altri beni $\gg^{165}$, agganciandosi così alla proposta di Longhi.

A prendere le difese del progetto, ma con un importante spostamento, interviene con un lungo plaidoyer Massari. Argomentando a partire dai limiti posti in via generale all'autotutela dall'art. 235 del Codice Zanardelli, Massari chiede che venga affermata in generale la legittimità della difesa di «tutti i beni giuridici». Il «solo limite», ricorda Massari, viene dato dall'esservi «una proporzione tra l'azione offensiva e la reazione difensiva», rifacendosi qui all'«ultimo progetto tedesco», secondo il quale la difesa non sarebbe più legittima «quando la reazione non è proporzionata all'offesa ${ }^{166}$. Corrispondentemente Massari chiede che venga confermato l'impianto del progetto, che prevede appunto una affermazione del diritto ad agire in legittima difesa a prescindere dal tipo di beni aggrediti, con la sola importante richiesta di ulteriore precisazione del criterio di proporzionalità ${ }^{167}$. Immediatamente a seguire e su invito di Gregoraci a spiegare «con precisione, di quali beni hanno inteso a parlare» intervengono «i compilatori del Progetto» e cioè Vincenzo Manzini e Arturo Rocco.

\footnotetext{
162 Ibidem.

$163 \ll$ La cosa è tanto più pericolosa, in quanto, non solo i giurati, ma la stessa magistratura, è già troppo proclive ad ammetterla» (ibidem).

164 «Ricorda, a questo proposito, che, in un concorso per la magistratura, la quasi unanimità dei candidati, al quesito se si potesse ammettere la legittima difesa a favore di colui, che poteva sottrarsi alla violenza con la fuga, rispose di sì» (ibidem).

${ }^{165}$ Ibidem.

166 Ivi, p. 164.

167 Ibidem.
} 
Manzini difende subito l'estensione della legittima difesa proposta da Alfredo Rocco. Manzini teorizza un diritto alla legittima difesa tendenzialmente 'totale', esercitato dal «galantuomo» contro il «manigoldo» in conformità allo «spirito dello Stato fascista »:

[Manzini] Concorda pienamente nella disposizione e, se fosse possibile, vorrebbe allargarla ad ogni "interesse giuridicamente tutelato", sostituendo con questa dizione quella di "diritto" [...] Osserva inoltre che l'avversione contro l'estensione della legittima difesa deriva da quella filo-criminalità, dipendente dai così detti immortali principi, per cui il galantuomo deve sacrificare se stesso, per preservare la preziosissima vita del primo manigoldo, da cui venga aggredito. Gli sembra che, dato specialmente lo spirito dello Stato fascista, si debbano invertire questi concetti, e si debba dare all'aggredito la massima efficienza di reazione, quando lo Stato non può fornirgli la sua tutela, perché non arriverebbe in tempo. In tutti i casi, in cui non sia possibile invocare la pubblica forza, deve essere lecito, alla forza privata, di rintuzzare le aggressioni di qualsiasi specie, che attentino a qualunque legittimo bene ${ }^{168}$.

Arturo Rocco è meno temperamentvoll di Manzini e affronta l'argomento da lontano, ma il risultato è lo stesso: il sostegno della legittima difesa proposta. Rocco ricostruisce dal punto di vista storico e sistematico l'istituto della legittima difesa, evidenziando il processo di formazione dello Stato con la progressiva limitazione del ricorso dei privati all'uso della forza:

Occorre risalire ai principi. Vi furono delle primitive fasi dell'evoluzione giuridica $[. .$.$] in cui la difesa dei propri diritti era affidata alla forza individuale$ privata di ciascuno. Ma appena lo Stato si consolidò, non poté permettere che ciascuno si facesse ragione da sé e lo vietò sotto sanzione penale (reato di esercizio arbitrario delle proprie ragioni) ${ }^{169}$.

Come esempio paradigmatico Arturo Rocco fornisce la recente «legge sui sindacati $\gg: ~ « L o$ Stato crea una magistratura del lavoro, dirime i conflitti fra le classi sociali, e in questo modo gli è possibile di vietare, sotto sanzione penale, lo sciopero e la serrata. Dunque, anche tra le classi, deve finire il periodo della difesa fatta con la propria forza $\gg^{170}$.

A questo punto Rocco deve spiegare per quale motivo nel caso della legittima difesa, implicitamente un caso speciale del caso generale della lotta o del conflitto «tra le classi», lo Stato non limiti con decisione l'uso della forza, ma anzi amplii l'ambito legale di tale uso: «Vi sono però delle eccezioni. La legittima difesa, che è un residuo storico dell'antica difesa privata, è il solo caso, in cui la legge ammette eccezionalmente che il privato possa far valere i propri di-

\footnotetext{
168 Ivi, p. 165.

169 Ibidem.

${ }^{170}$ Ivi, p. 165 sg.
} 
ritti, invece che ricorrendo all'Autorità giudiziaria e a quella amministrativa, adoperando la sua forza privata $\gg^{171}$.

Qui è interessante notare che Rocco non spiega per quale motivo vi sia questa «eccezione», per quale motivo il «residuo storico dell'antica difesa privata» sia «eccezionalmente» ammesso dal legislatore. Esplicitando quanto già detto da Rocco, si tratta allora nel caso della legittima difesa di una «difesa fatta con la propria forza» da parte delle «classi». Quali siano le classi in conflitto in generale e soprattutto in particolare nel caso della legittima difesa non viene detto da Rocco.

Rocco posiziona dal punto di vista discorsivo la legittima difesa «eccezionalmente» ammessa dallo Stato tracciandone doppiamente i confini. Da un lato essa viene distinta rispetto alla «vendetta privata», riconducendo la difesa del cittadino privato a quella «della società e dello Stato»:

È consentito al privato di farsi ragione da sé, difendendo legittimamente i propri diritti minacciati, quando lo Stato non potrebbe intervenire in nessun modo ad impedire che la minaccia di un danno si traducesse in danno; e ciò perché, data l'imminenza del pericolo, lo Stato non arriverebbe in tempo. In tal caso, insomma, il cittadino agisce come organo dello Stato, esercita privatamente una funzione pubblica di difesa dei diritti, che lo Stato riconosce e, usando la sua forza, agisce in conformità dell'interesse della società e dello Stato, per la conservazione della società e dello Stato ${ }^{172}$.

Dall'altro la legittima difesa viene distinta rispetto alla «mera difesa preventiva privata, diretta esclusivamente ad evitare le cause dell'azione illecita e dannosa $\gg^{173}:$ «Ma la legittima difesa si differenzia dalla difesa preventiva, perché ci deve essere la minaccia di violazione di un diritto, e non si può ammettere la legittima difesa contro un pericolo futuro, immaginario e non concreto $\gg^{174}$.

Questo viene ulteriormente concretizzato da Rocco, che esclude lo scivolamento verso una legittima difesa preventiva basata sul 'tipo di aggressore': «Uno non può legittimamente difendersi contro un individuo, che incontra in una strada solitaria, solo perché, dalla faccia, gli sembra un individuo pericoloso. Ed è perciò che si parla di pericolo e di offesa $\gg^{175}$.

Infine Rocco viene al punto centrale, quello dell'ampliamento della legittima difesa alla difesa dei beni patrimoniali. Egli critica l'art. 49 n. 2 del Codice Zanardelli, che permette la difesa dei «beni patrimoniali» solo «quando sia messa in pericolo la persona», facendo leva su di una Wertungslücke, una 'lacuna valoriale' della normativa del Codice Zanardelli: « Ma non sarà possibile respingere le offese ai propri beni patrimoniali, offendendo i beni patrimoniali

\footnotetext{
${ }^{171}$ Ivi, p. 166.

172 Ibidem.

173 Ibidem.

174 Ibidem.

175 Ibidem.
} 
altrui? Si dice: no; solo quando si tratta di un pericolo alla persona, si possono offendere i beni patrimoniali altrui $\gg^{176}$.

Una volta 'trovata la falla' e insinuato il dubbio sulla ragionevolezza del moderamen inculpatae tutelae sotteso alla disciplina del Codice Zanardelli, Rocco articola una sorta di bilanciamento di 'interessi'/'beni'. In un primo passaggio argomentativo tocca all'ipotesi in verità più innocua: «Per difendere un proprio bene superiore, è logico che si possa offendere un interesse minore altrui $\gg^{177}$.

In un secondo passaggio Rocco estende la portata di tale principio anche al caso appena tematizzato, quello in cui i beni ovvero gli interessi abbiano lo stesso peso ovvero siano 'equivalenti'. Qui il bilanciamento è risolto in forza della ingiustizia dell'aggressione, della offesa: $\ll[\mathrm{M}] \mathrm{a}$ anche se i due interessi sono pari, e voi agite illegalmente contro di me, io posso egualmente agire, per respingere l'offesa al mio interesse ${ }^{178}$.

Ne segue la legittimità della difesa a tutela dei beni patrimoniali consistente nella lesione dei diritti patrimoniali altrui, cosa del resto del tutto plausibile. Ma Rocco va oltre, e invece di limitarsi alla lesione dei soli diritti patrimoniali nega che l'aggressore abbia il «diritto al rispetto dei propri diritti», lasciando far capolino alla 'realtà' delle cose, all'eventualità che chi aggredisce la proprietà debba poter mettere in conto di perdere anche altri diritti, perché no, ben più preziosi e 'vitali' dei diritti patrimoniali: «Chi viola i diritti altrui, non ha diritto al rispetto dei propri diritti, di modo che deve essere lecito, per difendersi, d'offendere $i$ diritti patrimoniali altrui, non solo quando alla offesa dei propri diritti patrimoniali si accompagna il pericolo alla propria persona, ma anche in ogni altro caso $\gg^{179}$.

In tal modo Rocco arriva a giustificare la reazione lesiva dei beni patrimoniali dell'aggressore. Rocco non affronta però davvero l'hard case, il caso della difesa dei beni patrimoniali che comporti la violazione di un bene (essenzialmente) superiore ai beni difesi, esemplarmente: della vita. Basta qui l'illiceità? Egli offre sul punto una risposta solo implicita, nel momento in cui evoca come in un mantra risolutivo il principio di proporzionalità:

È tutta questione di proporzione. I diritti si devono poter difendere con la forza individuale, quando il pericolo è imminente e lo Stato non può intervenire; è però necessario che vi sia sempre proporzione, tra l'azione e la reazione, tra l'offesa e la difesa. Se questo concetto di proporzione non è ben chiaro, si può renderlo più chiaro, ma il principio dell'art. 54 non può essere mutato ${ }^{180}$.

In tal modo sul fragile ponticello del principio di proporzione Rocco indica la via per considerare legittimo il passaggio dalla difesa di beni patrimoniali lesiva di beni patrimoniali o equivalenti a quella lesiva di beni più rilevanti, come

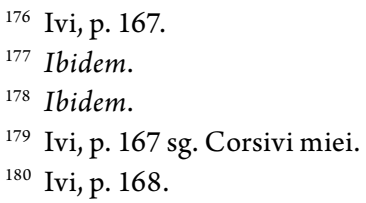


la vita e l'incolumità fisica, si badi bene: ammettendo che in realtà il ponticello che si sta costruendo e sul quale ci si deve muovere è piuttosto traballante e andrebbe riparato 'in corso d'opera'181.

In questo contesto discorsivo la limitazione data dalla «proporzione tra l'azione e la reazione, tra l'offesa e la difesa» resta necessariamente semanticamente vaga e aperta alla possibilità del prevalere del patrimonio dell'aggredito sulla vita dell'aggressore. La chiusura dal punto di vista argomentativo, che si collega implicitamente all'asserzione secondo cui «i diritti $\gg$ debbono poter essere difesi «con la forza individuale» è data dal passaggio finale del discorso di Rocco: «Conclude riaffermando il concetto che è necessario dare al privato onesto un'arma legittima, per difendere i suoi diritti, dove lo Stato non può intervenire a difenderlo. Questo concetto, specialmente nel nostro Regime, deve essere solennemente consacrato ${ }^{182}$.

Ora ci siamo: dare al privato, natürlich onesto - non certo disonesto, per cortesia - un'arma legittima che gli consenta di «difendere i suoi diritti» in assenza dello Stato. La legittima difesa diviene essa stessa un' «arma». Certo si tratta sempre di un'eccezione, ma è un'eccezione 'ben armata'. E le armi sono fatte per poter essere usate.

Qui, come in altri casi ${ }^{183}$, viene chiamato il sistema 'politica' a 'colonizzare' il 'diritto' e a sorreggere un'argomentazione non priva di debolezze. A questo punto interviene il consigliere Pujia, che è presidente e che, ricollegandosi implicitamente alla possibilità ventilata dallo stesso Rocco, di «render[e] più chiaro» il testo dell'articolo, propone di aggiungervi — «allo scopo di evitare ogni possibile contraria interpretazione» - l'enunciato «purché tra azione e reazione (oppure tra offesa e difesa) vi sia debita (o congrua) proporzione ${ }^{184}$. $\mathrm{E}$ interessante notare che alla proposta di Pujia, cui si associa espressamente Gregoraci, non è dato seguito in commissione. Questa infatti approva nella stessa seduta il testo così come presentato. La Relazione ci dice che il testo dell'art. 54 «u largamente discusso $\gg^{185}$. La Relazione ricorda come «a tutta prima» sembrasse «che la sostituzione del concetto di pericolo a quello di violenza attuale, nonché la dizione generica di diritti senza limitazione alcuna, estendessero soverchiamente il moderamen inculpatae tutelae» ${ }^{186}$. Questa impressione sarebbe stata pe-

${ }^{181}$ Nella risposta a Longhi Rocco affronta la questione della legittima difesa 'bagatellare', negando la liceità della difesa mortale di 'un grappolo d'uva' per mancanza di proporzione tra l'offesa $\mathrm{e}$ la difesa. La qual cosa non porta particolarmente lontano. Già due grappoli d'uva sembrano cominciare a diventare problematici! Sulla questione della limitazione del Notwehrrecht nel caso bagatellare nel diritto penale tedesco mi permetto di rimandare al mio Das Leben, cit., p. $57 \mathrm{sgg}$.

${ }^{182}$ Ministero della giustizia e degli affari di culto, Lavori, cit., p. 168. Corsivo mio.

${ }^{183}$ Vedi sopra l'argomentazione di Alfredo Rocco nel 1925 al Senato.

${ }^{184}$ Ivi, p. 169.

${ }^{185}$ Ministero della giustizia e degli affari di culto, Lavori, cit., vol. IV, parte IV. Verbali delle sedute della Commissione. (Libro II del Progetto: verbali dal n. 63 al n. 71) e relazione riassuntiva dei lavori della Commissione, Tipografia delle Mantellate, Roma 1929, p. 267 sg., p. 283.

${ }^{186}$ Ibidem. Corsivo nel testo originale. 
rò controbilanciata da altre osservazioni, facenti appunto leva sul carattere di novità e di cesura rappresentato dal fascismo e sul principio di proporzionalità:

Senonché, una volta spiegato ed accolto il concetto che nello Stato moderno e specialmente nell'attuale Regime spetti al cittadino il diritto di difesa nell'imminenza del pericolo, quando si ravvisi l'impossibilità dello intervento dei tutori dell'ordine sociale, e che l'applicazione della scriminante richiede sempre la proporzione tra pericolo e reazione, si finì coll'approvare il testo dell'articolo, formulando solo il voto che si studi il modo di comprendere, nei diritti in senso lato, tutti gli interessi legittimi tutelati dalle legge penale (vita umana, libertà personale, pudore, ecc. $)^{187}$.

In altri termini: due sono gli argomenti che ricompattano la commissione. Il primo è il 'richiamo all'ordine', di natura schiettamente politica: la questione dell'ampliamento della legittima difesa è una questione politica di primo piano per il regime fascista. Il secondo ha a che fare con il chiarimento fornito da Arturo Rocco nella discussione, per far venir meno l'impressione che la nuova disposizione potesse autorizzare difese del tutto sproporzionate, comel'uccisione per un fatto 'bagatellare' (la tutela del famigerato grappolo d'uva), insomma che venissero del tutto espunte dal requisito della necessità le imprescindibili considerazioni della qualità dei beni in conflitto.

\section{3. «Un colpo al cerchio e uno alla botte». La commissione parlamentare}

Nel 1929 il ministro Alfredo Rocco presenta al Re il Progetto definitivo. Il nuovo testo, che reca due importanti novità, è il seguente: «Art. 56 (Difesa legittima). Non è punibile colui che ha commesso il fatto, per esservi stato costretto dalla necessità di difendere un diritto proprio od altrui contro il pericolo attuale di un'offesa ingiusta, sempre che la difesa sia proporzionata all'offesa ${ }^{188}$.

Nella Relazione sul Progetto definitivo Alfredo Rocco illustra, agganciandosi implicitamente a quanto detto dal fratello Arturo in commissione ministeriale, la nuova configurazione dell' istituto della legittima difesa partendo dalla ratio dello stesso: «La difesa privata fu mezzo ordinario di tutela dei propri beni in tempi non civili, ma fu naturalmente bandita e punita correlativamente al progredire degli ordinamenti sociali e politici, che avocavano alle Autorità costituite nello Stato il mantenimento della pace sociale, assicurando a ciascuno ciò che gli spetta» ${ }^{189}$.

Da una parte vi sono $i$ «tempi non civili $\gg$ della $\ll$ difesa privata $\gg$ come $\ll$ mezzo ordinario di tutela», dall'altra vi sono implicitamente i 'tempi civili' della

${ }^{187}$ Ibidem. Corsivo nel testo originale.

${ }^{188}$ Ministero della giustizia e degli affari di culto, Lavori, vol. V. Progetto definitivo di un nuovo codice penale con la relazione del Guardasigilli on. Alfredo Rocco, parte III. Testo del Progetto definitivo, Tipografia delle Mantellate, Roma 1929, p. 20.

${ }^{189}$ Ministero della giustizia e degli affari di culto, Lavori, vol. V. Progetto definitivo di un nuovo codice penale con la relazione del Guardasigilli on. Alfredo Rocco, parte I. Relazione sul libro I del Progetto, Tipografia delle Mantellate, Roma 1929, p. 94 sgg., p. 95. 
'difesa da parte dello Stato', sempre come 'mezzo ordinario di tutela'. La difesa privata viene quindi spostata nell'ambito dell'eccezione rispetto alla regola:

Dovette però sempre riconoscersi che anche nelle società più perfettamente ordinate possono ricorrere momenti eccezionali, nei quali l'individuo non può attendere dalle Autorità la difesa dei propri diritti, per l'attualità del pericolo che incombe e che non consente remora alcuna, e fu giocoforza ammettere che in tali condizioni la difesa privata fosse legittima, purché proporzionata all'attacco, che si deve respingere ${ }^{190}$.

Le conseguenze sono formulate chiaramente: «Come vedesi, il fondamento dell' istituto non designa limiti ai diritti da tutelare, ma prevede condizioni imprescindibili per l'esercizio della tutela, ed a questi concetti si ispira l'articolo 56 del Progetto, anche in armonia con la tendenza dottrinale e legislativa oggi nettamente prevalente in tutte le Nazioni $\gg^{191}$.

Tramite il ricorso alla ratio dell'istituto viene costruita implicitamente una legittima difesa come una generale facoltà, un diritto ad agire in generale con l'uso della violenza a tutela dei propri diritti, tendenzialmente, in forza della ratio stessa, illimitato. La legittima difesa diviene sempre più diritto alla legittima difesa. Rocco ricostruisce dal punto di vista sistematico gli elementi o requisiti essenziali del nuovo istituto della legittima difesa. L'istituto viene a essere caratterizzato dai tre requisiti del «pericolo attuale dell'offesa», della «conseguente necessità della difesa» e della «proporzione tra l'azione e la reazione». Per quanto concerne il primo requisito, Rocco ricorda come il Progetto si sia «esplicitamente [...] riferito al pericolo dell'offesa e non all'offesa» ${ }^{192}$. Questo sarebbe da ricondurre secondo Rocco alla circostanza che «la legittima difesa opera contro un pericolo e non reintegra una situazione giuridica già pregiudicata, poiché in questa seconda ipotesi l'offesa costituisce già un fatto compiuto, ed anche filologicamente, oltre che giuridicamente, non potrebbe trovare applicazione la nozione di difesa ${ }^{193}$. Quanto al secondo requisito, il «rapporto di necessità $[. .$.$] tra l'azione e la reazione», questo sarebbe «scolpito nell'esplicito$ richiamo all'attualità del pericolo ${ }^{194}$. Con riferimento al terzo requisito Rocco si mostra conciliante:

Quanto all'altro requisito, quello della proporzione tra l'offesa e la difesa, sembravami che esso fosse insito nell'aggettivo "grave", che qualifica l'offesa e nella successiva previsione dell'eccesso nella legittima difesa contenuto nell'art. 59. Ma poiché da molti si è insistito nel richiederne espressa menzione, e la

\footnotetext{
${ }^{190}$ Ivi, p. 95 sg. Corsivo mio.

191 Ivi, p. 96.

192 Ibidem.

${ }^{193}$ Ibidem.

${ }^{194}$ Ibidem.
} 
Commissione ministeriale ha proposto analogo voto, ho aggiunto nel testo le seguenti parole: "sempre che la difesa sia proporzionata all'offesa minacciata"195.

Qui Rocco glissa sul particolare che a tale 'aggiunta' corrisponde la 'sottrazione' del requisito della gravità dell'offesa. Se ora la difesa deve essere espressamente «proporzionata all'offesa», l'offesa minacciata non è più espressamente «grave». Esattamente questo punto sarà oggetto di controversie nella commissione parlamentare incaricata da Rocco di dare parere sul Progetto definitivo. Rocco trasmette il 27 ottobre 1929 il Progetto definitivo al presidente del Senato, perché convochi assieme al presidente della Camera l'apposita commissione parlamentare prevista dalla legge 2260 del 24 dicembre 1925. Nella lettera di accompagnamento del 27 ottobre 1929, premessa al volume VI degli Atti della commissione parlamentare, Alfredo Rocco chiarisce alla commissione quale sia l'ambito in cui si muove il Progetto. Due sono le novità che vengono sottolineate. La prima posiziona nella società la politica del diritto penale sottesa al Progetto. Secondo Rocco il Progetto definitivo terrebbe «conto delle mutate condizioni sociali che reclamano la riforma degli istituti vigenti per potere apprestare mezzi più efficaci di lotta contro la criminalità ${ }^{196}$. La seconda collega invece la politica penale 'securitaria' sottesa al Progetto con la politica tout court: «[Il Progetto definitivo del nuovo Codice penale] si ispira completamente ai postulati fondamentali della Dottrina e della Rivoluzione Fascista assicurando, secondo la volontà illuminata del DUCE, il vigile presidio e la salda difesa degli interessi dello Stato ${ }^{197}$.

La Commissione parlamentare per il Codice penale, composta ex art. 2 della legge 24 dicembre 1925 n. 2260, si riunisce nella prima seduta plenaria del 14 novembre 1929, per poi suddividere il lavoro in tre sottocommissioni. La sottocommissione cui tocca esaminare il Libro I del Progetto, contenente tra l'altro la disciplina della legittima difesa, è composta dai senatori D’Amelio, che la presiede, De Blasio e Stoppato, dai deputati De Marsico, Fera e Solmi e dal consigliere di Cassazione Aloisi. La disciplina della legittima difesa viene esaminata in due sedute. Nella prima seduta del 19 dicembre 1929, in particolare, il requisito della 'proporzione tra l'offesa e la difesa' non viene ritenuto sufficiente a delimitare efficacemente la legittima difesa. Così secondo De Blasio «l'impunità per legittima difesa è di un'ampiezza enorme. Nei Tribunali e nelle Corti non vi sarà causa in cui non si sosterrà che il fatto avvenne in istato di legittima difesa e che essa fu proporzionata all'offesa $>^{198}$. Tre sono le fattispecie che preoccupano De Blasio: inseguimento e uccisione del ladro «per riprendere il portafoglio rubato»; uccisione di chi «percuota altri ingiustamente»; uccisio-

\footnotetext{
195 Ibidem.

${ }^{196}$ Ministero della giustizia e degli affari di culto, Lavori, cit., vol. VI. Atti della commissione parlamentare chiamata a dare il proprio parere sul progetto di un nuovo Codice penale, Tipografia delle Mantellate, Roma 1930.

197 Ibidem. Maiuscolo nel testo originale.

198 Ivi, p. 84.
} 
ne «per evitare il pericolo attuale di ingiurie o di altre offese ingiuste» ${ }^{199}$, anche alla luce del fatto che è stato eliminato il requisito della 'gravità' dell'offesa. Per De Blasio sarebbe necessario «considerare prevalentemente la persona». A suo parere non vi sarebbe «Codice in cui la legittima difesa faccia astrazione dal pericolo della persona $\gg^{200}$.

Nella discussione che si accende sul punto si arriva velocemente al problema dell'interpretazione della richiesta 'proporzione tra difesa e offesa'. Secondo il presidente della commissione D'A melio «la proporzionalità si riferisce all'entità dell'offesa e non all'importanza del diritto leso, mentre è quest'ultima proporzione che bisogna stabilire $\gg^{201}$. D'Amelio fonda la sua asserzione nel seguente modo:

Dicendosi difesa proporzionata all'offesa si ha l'impressione che si voglia fare riferimento solo alla forza offensiva e non anche all'entità del diritto. Ciò non può lasciar tranquilli, perché non si può ammettere che per un oggetto di valore infimo si possa opporre una difesa sproporzionata, lesiva di un diritto molto più importante della controparte ${ }^{202}$.

E ancora più esplicitamente: «[...]. Quando si dice che si deve proporzionare la difesa all'offesa si può finire col giustificare qualunque atto violentissimo che sia compiuto in difesa di un diritto trascurabile $\gg^{203}$.

AD'Amelio replica subito il collega Aloisi, secondo il quale in tal caso «occorrerebbe che anche l'offesa minacciata (attualmente, come specifica il Progetto) fosse stata del pari violentissima. Allora soltanto sussisterebbe quella proporzione tra la difesa e l'attacco, che è indispensabile perché la prima sia legittima. Di fronte alla violenza dell'offesa minacciata, la qualità del diritto in pericolo sembra irrilevante $\gg^{204}$. A questo punto dinanzi al pericolo di una deriva interpretativa la commissione parlamentare si ferma e preferisce tornare a lidi più conosciuti. Il commissario Solmi sottolinea come «il concetto della proporzione applicato in modo troppo semplice sia pericoloso $»^{205}$. Secondo Solmi $\ll$ converrebbe forse tornare alla dizione del Progetto preliminare, dove si parlava di pericolo attuale di un'offesa grave e ingiusta ${ }^{206}$. Il termine «grave» farebbe «subito pensare a un elemento di una qualche importanza». Questo verrebbe a completare e precisare «il concetto della legittima difesa» nel senso evocato da D'Amelio. Quanto alla «proporzione della difesa all'offesa», questa sarebbe «implicita» nella disposizione sull'eccesso colposo. Alla fine la sottocommissione decide di chiedere il ripristino della disposizione del progetto preliminare originario del

\footnotetext{
199 Ibidem.

${ }^{200}$ Ivi, p. 85.

201 Ibidem.

${ }^{202}$ Ibidem.

203 Ibidem.

${ }^{204}$ Ibidem.

205 Ivi, p. 86.

206 Ibidem.
} 
1927 e di chiedere in subordine l'aggiunta della proporzione della difesa «oltre che all'offesa, anche all'entità del diritto da difendere».

L'ambiguità della nuova formulazione aggiunta da Alfredo Rocco a seguito della discussione in commissione ministeriale domina anche l'ulteriore discussione nella commissione parlamentare, questa volta in composizione 'plenaria' sotto la presidenza di D’Amelio, nella seduta del 14 marzo 1930. Due sono le posizioni che si confrontano e danno vita a diverse mozioni. La prima rigetta del tutto il testo e chiede il mantenimento dell'art. 49 del Codice Zanardelli. Secondo Stoppato, cui De Blasio si associa, la formula dello Zanardelli sarebbe «molto più precisa». La nuova disposizione estenderebbe «eccessivamente [...] il concetto della legittima difesa $»$. Inoltre, non verrebbe indicato «se non troppo genericamente il diritto che si intende difendere, ciò che permetterebbe di credere che la difesa sia ammissibile, qualunque sia la natura di tale diritto». Stoppato in altre parole fa valere il topos argomentativo con cui si difende la normativa dello Zanardelli: l'ampliamento sarebbe troppo ampio, generico, non riferito ai singoli diritti, implicitamente: alla persona. La conclusione è chiara: $\ll$ Si dovrebbe pertanto adottare una formula più cauta e rigida, per evitare applicazioni pericolose dell'istituto ${ }^{207}$.

Il pericolo evocato da Stoppato è implicitamente quello di una deformalizzazione e quindi di un allentamento dei requisiti formali della fattispecie della legittima difesa, con la contestuale creazione di ampi spazi per una possibile interpretazione 'creativa', troppo creativa, in breve: politica da parte dei giudici. Contro le argomentazioni di Stoppato, a difesa del testo di legge proposto argomenta in particolare Aloisi, che difende espressamente la scelta di Alfredo Rocco di inserire la clausola di proporzione e togliere il requisito della «gravità» dell'offesa ${ }^{208}$.

$\mathrm{Si}$ arriva infine alla votazione finale. Vengono formulate le seguenti proposte: 1) la proposta radicale di «ripristinare» ovvero mantenere l'articolo 49 del Codice Zanardelli ${ }^{209}$; 2) la proposta di modificare la disposizione del Progetto «sostituendo la parola "respingere" alla parola "difendere"»; 3) la proposta di «integrare l'articolo 56 con la proporzione fra la difesa e il bene offeso», e quindi di esplicitare almeno dalla parte dell'aggressore il rapporto di proporzione tra $\mathrm{i}$ beni in conflitto; 4) la proposta di mantenere l'articolo 56 nella forma datale dal ministro Rocco ${ }^{210}$. Per prima viene messa ai voti e non approvata la mozione più radicale, quella di «ripristino dell'art. 49». Quindi viene messa ai voti una mozione che intende in un certo senso integrare le proposte di cui ai nn. 2 e 3, consistente nella richiesta di «mantenimento dell'art. 56» assieme alla «specificazione che la difesa deve essere proporzionata non soltanto all'offesa, ma anche all'entità del diritto che si vuole difendere». Tale mozione viene approvata. A essa la commissione aggiunge l'ulteriore raccomandazione al ministro di «so-

\footnotetext{
${ }^{207}$ Ivi, p. 428.

${ }^{208}$ Ivi, p. 428 sg.

${ }^{209}$ Ivi, p. 429.

${ }^{210}$ Ivi, p. 429 sg.
} 
stituire la parola "respingere" alla parola "difendere"» e di tenere «anche presente le altre osservazioni fatte sull'art 59» ovvero in tema di eccesso colposo ${ }^{211}$.

\subsection{L'epilogo}

Rocco non tiene conto del parere della commissione parlamentare. Anzi, nella Relazione al Re, Alfredo Rocco chiarisce la sua posizione ${ }^{212}$, ricordando, e implicitamente rispondendo alle critiche della commissione parlamentare, che con l'aggiunta del requisito della proporzione tra offesa e difesa non si è voluto introdurre una proporzione tra i diritti in gioco:

La difesa deve essere proporzionata all'entità dell'offesa e non necessariamente all'importanza dell'interesse che si vuole difendere. Anzi, l'aggressione denota, non di rado, tanto maggiore pericolosità quanto meno rilevante è il bene aggredito. Non si nega che, talvolta, anche l'importanza dell'interesse da difendere possa costituire un elemento per giudicare della gravità dell'offesa, ma non è mai questo un elemento essenziale e non può mai essere l'unico elemento di valutazione della legittimità della difesa. La gravità dell'offesa consiste nella gravità del pericolo, nel modo, cioè, in cui si offende (circostanze e modalità $)^{213}$.

In tal modo torna l'idea di utilizzare la legittima difesa come strumento per difendere la società contro gli individui 'temibili' e 'pericolosi', la cui temibilità e pericolosità viene indiziata dalla commissione di delitti meno gravi, implicitamente: soprattutto delitti contro la proprietà. Il legislatore fascista 'risolve' il «conflitto di classe» tra i 'proprietari' e i 'non proprietari' che ricorrono al furto, dando la prevalenza ai 'proprietari'.

Con un'ulteriore modifica inessenziale, e cioè con la sostituzione del pronome «colui che» con «chi», il testo verrà definitivamente approvato come art. 52 del Regio decreto 19 ottobre 1930 n. 1398, del cosiddetto Codice Rocco: $\ll$ (Difesa legittima). Non è punibile chi ha commesso il fatto per esservi stato costretto dalla necessità di difendere un diritto proprio od altrui contro il pericolo attuale di un'offesa ingiusta, sempre che la difesa sia proporzionata all'offesa».

${ }^{211}$ Ivi, p. 430. Quanto al riferimento alle «osservazioni sull'art. 59» si veda ivi, p. 428 sg.

${ }^{212}$ Questo viene già ricordato da Marciano nella sua ricostruzione del dibattito sul nuovo testo della legittima difesa, in G. Marciano, Il nuovo Codice penale. (Innovazioni), Jovene, Napoli 1932, p. 81. Marciano si esprime tra l'altro criticamente nei confronti della nuova disposizione ritenendola più restrittiva di quanto lo sia la disposizione relativa del Codice Zanardelli (ivi, p. 81 sgg.).

${ }^{213}$ Ministero della giustizia e degli affari di culto, Lavori, vol. VII. Testo del nuovo Codice penale con la Relazione a Sua Maestà il Re del Guardasigilli (Rocco), Tipografia delle Mantellate, Roma 1930, p. 49 sg. 


\section{Conclusioni}

Il diritto penale 'liberale', che ispira ancora la disciplina della legittima difesa del Codice Zanardelli del 1889, resta ancorato alla concezione 'tradizionale', propugnata dalla Scuola classica nella scia di Beccaria (esemplarmente: Carrara) che vede la legittima difesa come un'eccezionale autorizzazione dell'uso della forza mortale a tutela della vita e dell'incolumità fisica. Il requisito della «violenza» di cui all'art. 49 del Codice Zanardelli rimanda a una difesa mirata a proteggere da aggressioni alla vita o all'incolumità fisica e quindi, con progressivo allontanamento dal 'cuore' della disposizione, del pudore e della libertà, non invece della proprietà, difendibile solo nel momento in cui il proprietario aggredito si trovi in un pericolo per la vita o l'incolumità fisica (art. 376). La Scuola positiva (per tutti: Fioretti), che vuole lottare contro le $\ll$ nebulose disquisizioni dei filosofi del diritto», prende di petto la concezione liberale, proponendo un paradigma nel quale la legittima difesa diviene, da scusante o al massimo giustificazione calibrata solo su alcuni tipi di beni personali, un vero e proprio diritto a difendere tendenzialmente tutti i beni o diritti, in particolare la proprietà. Questa viene infatti messa sempre più in questione nel XIX secolo dalle masse che lo stato liberale stenta a integrare. La risposta dell'apparato statale è piuttosto la repressione, e la 'questione sociale' viene trasformata in 'questione criminale', per 'difendere la società' dalle 'aggressioni' della delinquenza. I frutti del lungo assedio fatto dalla Scuola positiva ai bastioni liberali della Scuola classica vengono colti dal fascismo. Nel progetto di riforma del Codice penale presentato nel 1927 si impone l'idea di legittima difesa come difesa fondamentalmente di tutti i diritti, e quindi anche della proprietà, tramite simbolica 'incorporazione' dei proprietari in armi nel dispositivo difensivo dell'apparato statale. Proprio questa trasformazione della legittima difesa viene percepita come un pericoloso attacco al monopolio statale della violenza legittima da parte della Cassazione nel suo parere sulla disposizione proposta: va bene il fascismo; va bene pure la necessitas. Anzi: «di fronte alla necessità è mestieri inchinarsi $\gg$, ricorda la Cassazione, per poi subito tracciare dopo tale 'inchino' a mo' di confine per le 'ragioni' della necessità «la limitata cerchia della difesa personale, oltre la quale si va verso l'anarchia ${ }^{214}$. Se la necessitas oltrepassa tale limite, si affaccia prepotente il pericolo di un'escalation nell'impiego della forza fisica giuridicamente e politicamente inaccettabile. In altri termini, come fatto balenare dalla Cassazione nel suo parere, se lo Stato fascista è davvero così forte come sostiene di essere, per quale ragione vuole armare i cittadini perché intervengano là dove invece dovrebbe arrivare lo Stato stesso in prima persona? La contraddizione è palese. L'intervento risoluto della Cassazione a favore dello Stato liberale contro lo Stato fascista, in realtà - per quel che riguarda la questione della limitazione del ricorso all'impiego della violenza fisica da parte dei privati - meno forte e sicuro di sé di quello liberale, costituisce il filo conduttore dello scontro sulla nuova disposizione del Progetto di Codice del 1927, che porterà, passando per accese discussioni

${ }^{214}$ Ministero della giustizia e degli affari di culto, Osservazioni, cit., p. 395. 
prima nella commissione ministeriale e poi nella commissione parlamentare, alla modifica della disposizione originaria, in particolare tramite la previsione del requisito di proporzione tra offesa e difesa. Il punto che la Cassazione coglie così acutamente nella discussione del Progetto del Codice del 1927, smascherando l'essere il regime fascista in realtà non veramente interessato alla forza dello Stato, ma piuttosto al suo indebolimento, fornendo ai «privati onesti» la difesa legittima, cioè con le parole di Arturo Rocco «un'arma legittima, per difendere i suoi diritti, dove lo Stato non può intervenire a difenderlo», viene colto con almeno altrettanta chiarezza in termini generali dal sociologo Niklas Luhmann nella sua Rechtssoziologie. Secondo Luhmann la violenza fisica costituisce certo per la sua «funzione simbolica», per il suo rappresentare la possibilità del ricorso alla forza nel caso in cui vengano deluse le aspettative del comportamento conforme al diritto, un momento ineliminabile del diritto. Essa «accompagna il diritto come un'ombra incancellabile $\gg^{215}$. Ma questo è solo il punto di partenza. Due sono i «problemi principali» che nascono con la «associazione di diritto e violenza» ${ }^{216}$. Il primo è dato dalle strutturali, purtroppo probabili uccisioni e lesioni 'inizialmente non necessariamente previste'. Il secondo ha a che fare con la circostanza che «la violenza fisica ha la caratteristica peculiare di possedere un'alta indipendenza dalla struttura ${ }^{217}$. Il che significa che essa presuppone $<$ soltanto una forza preponderante, ma non precisi sistemi di status, contesti di ruoli, appartenenze a determinati gruppi, distribuzione di informazioni, rappresentazioni valoriali» ${ }^{218}$. Mancano insomma gli effetti positivi dati dall'organizzazione in termini di potere. A questo si aggiunga infine che la violenza fisica è «pressoché impiegabile universalmente, e cioè ampiamente indifferente nei confronti del momento, della situazione, dell'oggetto e dell'ambito di senso (Sinnzusammenhang) dell'azione; essa è quindi anche separabile nella indicazione degli scopi dalle strutture esistenti» ${ }^{219}$. Questo comporta che la Gewalt, la violenza fisica resta «einheitlich organisierbar, wie komplex das Recht auch werden mag ${ }^{220}$, «organizzabile unitariamente, indipendentemente da quanto possa divenire complesso il diritto». Insomma: la violenza fisica ha il difetto di poter essere applicata a 360 gradi, di essere un mezzo che è indipendente dai fini rispetto ai quali viene impiegato, di mostrarsi alquan-

${ }^{215}$ N. Luhmann, Rechtssoziologie, Band 1, Rowohlt, Reinbek bei Hamburg 1972, p. 110: «Die physische Gewalt begleitet das Recht wie ein unabwerfbarer Schatten, aber gewisse Probleme, die mit dieser Assoziierung von Recht und Gewalt verbunden sind, lassen sich in komplexeren Gesellschaften besser lösen».

${ }^{216}$ Ibidem.

${ }^{217}$ Ibidem.

$218 \ll$ Sie ist von Systemstrukturen weitgehend unabhängig, da sie eben nur überlegene Kraft, nicht aber bestimmte Statusordnungen, Rollenzusammenhänge, Gruppenzugehörigkeiten, Informations verteilungen, Wertvorstellungen voraussetzt» (ibidem).

219 «Überdies ist physische Gewalt nahezu universell verwendbar, nämlich weitgehend indifferent gegen Zeitpunkt, Situation, Objekt und Sinnzusammenhang der Aktion; sie läßt sich also auch in ihren Zielsetzungen von vorhandenen Strukturen ablösen» (ibidem).

${ }^{220}$ Ibidem. 
to 'volatile' e quindi alla lettera 'distruttiva' per quel che concerne il suo impiego: $\ll$ la violenza fisica può puntellare come distruggere l'ordinamento dato ${ }^{221}$. In altri termini: una pistola può essere usata contro un killer che voglia realizzare il suo proposito omicida penetrando nottetempo nell'abitazione della sua vittima come contro l'incolpevole moglie o gli incolpevoli figli, i vicini troppo rumorosi o il malcapitato automobilista che commetta un'infrazione ai danni del nervoso 'cittadino armato', contro il malcapitato migrante o il membro di un gruppo politico in competizione percepito addirittura come 'traditore'. Questo fa sì che, a differenza delle società primitive, le società più complesse, come quelle moderne, per la propria stabilità e quindi anche per la 'sicurezza' dei propri componenti preferiscano spostare la violenza fisica il più possibile nel retroscena, come una sorta di 'vera' extrema ratio, che garantisca non più le singole norme ma il sistema giuridico nel suo complesso ${ }^{222}$. Segue che non si crea più solo la «aspettativa» che la singola norma venga osservata, pena l'impiego della violenza per ristabilirne la vigenza, ma si crea in generale «l'aspettativa che altri si aspettino che il diritto sia garantito dalla violenza fisica» ${ }^{223}$. L'ulteriore livello di riflessione raggiunto consente di ricorrere a tutta una serie di soluzioni giuridiche 'intermedie' fatte di 'adeguatezza' e di 'proporzionalità. Ancora con le parole di Luhmann:

Anche e proprio nella società moderna, altamente complessa, l'assicurazione del potersi aspettare delle aspettative è molto più importante della assicurazione della realizzazione di aspettative. Nel caso di disturbi, vi sono più che mai soluzioni di seconda battuta, ausilii, possibilità di ottenere dei sostituti e compensazioni che possono essere organizzate e adottate ad hoc ${ }^{224}$.

Ne segue che la violenza «perde la sua qualità simbolica, passandola alla decisione. La selettività dell'ordinamento si manifesta ora nelle decisioni» ${ }^{225}$. Nel momento in cui sono le decisioni giuridiche a entrare in primo piano relegando nell'ombra la (pur sempre necessaria) violenza fisica, il sistema giuridico guadagna in stabilità e quindi in 'sicurezza'. La società viene disarmata con successo. Luhmann ricorda che igreci antichi vantavano «come caratteristica della loro Polis $[\ldots]$ che non c'è bisogno di portare con sé le armi, quando si va in strada ${ }^{226}$. Il

${ }^{221}$ Ivi, p. 111.

${ }^{222}$ Ivi, p. 114. Il «tenere pronta la violenza fisica» è «indispensabile per motivare singoli riottosi, ma prima di tutto è indispensabile per la produzione di una fiducia generalizzata nel diritto [Gesamtvertraue[n] in das Recht], cioè sul piano dell'aspettativa dell'aspettativa [Erwarten[s] des Erwartens]» (ibidem).

${ }^{223}$ Ibidem.

224 «Auch und gerade in der hochkomplexen, modernen Gesellschaft ist die Vergewisserung der Erwartbarkeit von Erwartungen sehr viel wichtiger als die Sicherung der Erfüllung von Erwartungen. Bei Störungen gibt es mehr denn je zweitbeste Lösungen, Aushilfen, Substitutionsmöglichkeiten und Kompensationen, die ad hoc organisiert und beschafft werden können» (ivi, p. 114 sg.).

${ }^{225}$ Ivi, p. 115.

${ }^{226}$ Ibidem. 
vantaggio di una tale concezione è evidente. Gli effetti indesiderati della violenza vengono ridotti il più possibile: «Con ciò si riduce il carico di conseguenze della violenza: il numero dei morti, invalidi, orfani e vedove colpevoli e innocenti, il numero dei disturbi funzionali nella "struttura" delle interazioni ${ }^{227}$. In tal modo il diritto secondo Luhmann si adegua «se non ai precetti di umanità, certamente ai requisiti di una società differenziata dal punto di vista funzionale ${ }^{228}$. In altri termini: non è solo una (sia chiaro: fondamentale) questione di humanitas quella dell'impedimento della barbarie! È pure una questione squisitamente 'giuridica' in termini di mantenimento del sistema giuridico stesso! Si spiega in tal modo per quali ragioni il tentativo di ottenere sicurezza ampliando l'ambito del ricorso alla violenza fisica da parte dei privati rischi di risultare disfunzionale rispetto ai fini dichiarati, se non addirittura distruttivo della ricercata sicurezza, come ricordato a suo tempo al regime fascista dalla Cassazione.

227 «Damit reduziert sich die Folgelast der Gewalt: die Zahl der schuldigen und unschuldigen Toten, Verstümmelten, Waisen und Witwen, die Zahl der funktionellen Störungen im Gefüge der Interaktionen» (ibidem).

${ }^{228}$ Ibidem. 